\title{
Advances in designing heterojunction photocatalytic materials
}

\author{
Zongpeng Wang a,b, Zhiping Lin a,c, Shijie Shen a,c, Wenwu Zhong a,c,*, Shaowen Cao b,\# \\ a School of Advanced Study, Taizhou University, Taizhou 318000, Zhejiang, China \\ b State Key Laboratory of Advanced Technology for Materials Synthesis and Processing, Wuhan University of Technology, Wuhan 430070, Hubei, China \\ c School of Pharmaceutical and Material Engineering, Taizhou University, Taizhou 318000, Zhejiang, China
}

\section{A R T I C L E I N F O}

\section{Article history:}

Received 29 April 2020

Accepted 10 July 2020

Available online 22 September 2020

\section{Keywords:}

Photocatalyst

Heterojunction

Renewable energy

Charge transfer

Redox ability

\begin{abstract}
A B S T R A C T
Under the background of increasing energy crisis and global warming, semiconductor-based photocatalysis has received tremendous attention due to its potential application in green energy production, $\mathrm{CO}_{2}$ reduction and pollutant degradation. The photocatalytic activity of semiconductors, however, remains low due to issues like fast recombination of photo-generated electron-hole pairs, limited electron mobility, restricted optical absorption or insufficient active sites. Designing appropriate heterojunctions is proved to be a promising method to address most of these issues and thus to improve the photocatalytic performance. In this review, the working mechanism of various heterojunctions is presented systematically. The most recent advances of strategies in designing and preparing efficient heterojunction photocatalysts are further summarized and some perspectives on the future directions in this field are provided.
\end{abstract}

(C) 2021, Dalian Institute of Chemical Physics, Chinese Academy of Sciences. Published by Elsevier B.V. All rights reserved.

\section{Introduction}

Technology explosion has made the human society unprecedentedly convenient and civilized since the first industrial revolution. Along with the rapid development of the whole world, however, major threatens that can influence millions of people are buried. Examples are energy crisis, environment pollution and global warming. On May 11, 2019, Mauna Loa Observatory reported that the $\mathrm{CO}_{2}$ level in the atmosphere had surpassed $415 \mathrm{ppm}$, which is the highest record through the whole human history. Tong et al. suggested the energy infrastructure has to be updated if the mean global warming is to be limited to $2{ }^{\circ} \mathrm{C}$ [1]. Successively, EU announced climate emergency in November 2019. Thus, it is urgent to develop green energy technologies to minimize the usage of fossil fuels and reduce the production of pollutants [2,3]. Photocatalysis is one of the most promising candidates to address these issues, which can directly utilize solar energy to produce hydrogen from water splitting [4-8], to convert $\mathrm{CO}_{2}$ into valuable chemicals [9-13] (such as $\mathrm{CH}_{4}, \mathrm{CO}, \mathrm{CH}_{3} \mathrm{OH}$, etc.), to degenerate organic pollutants [14-17], and to facilitate organic synthesis [18-23], as shown in Fig. 1.

Numerous semiconductors have been proposed as candidate photocatalysts and have been well studied, such as $\mathrm{TiO}_{2}$ [24-29], CdS [30-35], $\mathrm{ZnO}$ [36-38], $\mathrm{BiVO}_{4}$ [39-41], $\mathrm{C}_{3} \mathrm{~N}_{4}$ [42-50] and so on. However, these semiconductors suffer from some drawbacks that hinder their practical application, which motivates the development of heterojunction-based photocatalysts. For example, $\mathrm{TiO}_{2}$ and $\mathrm{ZnO}$ possess a band gap of $\sim 3.2 \mathrm{eV}$, which corresponds to the ultraviolent radiation. Thus,

\footnotetext{
* Corresponding author. E-mail: zhongww@tzc.edu.cn

\# Corresponding author. E-mail: swcao@whut.edu.cn

This work was supported by Key Research and Development of Ministry of Science and Technology of China (2018YFE0202601), the National Natural Science Foundation of China (11947070, 51572183, 51922081, 21773179), Materials Science \& Engineering of Zhejiang Province First-Class Discipline (P61021902), and the Natural Science Foundation of Zhejiang Province (LTY20E020001).

DOI: 10.1016/S1872-2067(20)63698-1 | http://www.sciencedirect.com/science/journal/18722067 | Chin. J. Catal., Vol. 42, No. 5, May 2021
} 


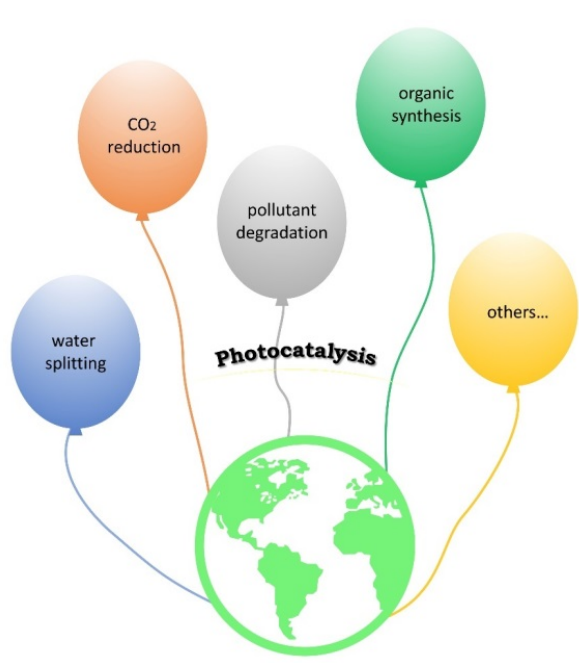

Fig. 1. Versatile applications of photocatalysis.

$\mathrm{TiO}_{2}$ or $\mathrm{ZnO}$ can only be excited by a small portion of solar energy. To boost the light utilization, one way is to introduce doping energy level in the band gap of the wide-bandgap semiconductors. Metal elements (such as $\mathrm{Co}, \mathrm{Ni}, \mathrm{Cr}$ etc.) or nonmetal elements (such as $\mathrm{C}, \mathrm{N}, \mathrm{S}$ etc.) have been used to dope $\mathrm{ZnO}$ or $\mathrm{TiO}_{2}$, to improve their visible absorption [51-54]. On the contrary, $\mathrm{CdS}, \mathrm{Cu}_{2} \mathrm{O}, \mathrm{BiVO}_{4}$ and some others possess a band gap in the visible range inherently. A narrower band gap can prompt the absorption of solar energy. However, the narrower band gap reduces the reducing/oxidizing ability of the photogenerated electrons/holes inevitably. Another critical concern that limits the photocatalytic activity of these semiconductors is the fast recombination rate of photogenerated electron-hole pairs. For instance, the lifetime of excitons in $\mathrm{ZnO}$ is estimated to be several hundreds of picoseconds [55,56], which is too short for redox reactions to efficiently utilize the electron-hole pairs.

To suppress the recombination of electron-hole pairs and retain their reducing and oxidizing ability, special strategies are required to design optimal photocatalysts. Heterojunction design has become one of the most promising approaches, with benefits of high light harvesting, retarded electron-hole recombination and fast charge transportation. Various heterojunction materials have been prepared and proved to be effective within this framework. Generally, those heterojunctions can be categorized according to the adjacent band structures into several types: p-n heterojunction, conventional type II heterojunction, Schottky heterojunction and S-scheme heterojunction. Compared with others, the recent proposed S-scheme heterojunction is a young and competent strategy that inspires lots of works in the past years $[57,58]$. Beyond those aforementioned, there are two special heterojunctions, namely the surface heterojunction and graphene-based heterojunction. Different lattice planes of a crystal can exhibit very distinct band structures. Thus, a band alignment similar to that of a heterojunction can be formed within a single-crystalline semiconductor with different exposed facets, which could enhance largely the photocatalytic activity of the semiconductor. Graphene possesses unique band structure and the huge specific surface area, which makes it a promising material for the fabrication of efficient photocatalysts. The band structure of graphene can be tuned through versatile ways, enabling the possibility of forming various types of heterojunctions with other semiconductors. In addition, the high electrical conductivity and large surface area make graphene a suitable material for the loading of photocatalysts, improving the overall activity. Composites based on graphene have also become a vital branch of the photocatalyst family.

In this review, we aim to present the most recent advances in the design and preparation of heterojunction photocatalysts, to summarize the basic strategies for achieving high-performance heterojunction photocatalysts and to give some perspectives on the future opportunities toward the development of highly efficient photocatalytic materials. We will first discuss the principles why heterojunctions can facilitate the photocatalytic efficiency. Then, the above-mentioned types of heterojunctions will be introduced respectively. In the end we will give a summarization and predict some future opportunities.

\section{Mechanism and principle}

Generally speaking, a photocatalyst-mediated redox reaction includes four processes, as illustrated in Fig. 2. (1) The photocatalyst absorbs solar energy under light illumination, with the excitation of electron-hole pairs. Thereafter, the solar energy is converted into energy stored in the excitons. (2) The photo-generated electrons and holes migrate to the surface of the photocatalyst. (3) The photocatalyst adsorb reactants on its surface. (4) The reactants are reduced/oxidized by electrons/holes and the products desorb from the photocatalyst surface. After this step, the photo-generated excitons are eliminated, and the stored energy is finally converted into chemical energy saved in the products. The photocatalyst returns to the initial state and is ready to another reaction cycle. Unfortunately, the second step encounters a serious competing process. Most generated electron-hole pairs tend to recombine to emit light or dissipate as heat, instead of migrating to the surface and participating in redox reactions. The recombination of electron-hole pairs is the main obstacle that hinders the improvement of the photocatalytic efficiency, and thus the prior issue heterojunctions are expected to address.

Fast separation of photo-generated electrons and holes is

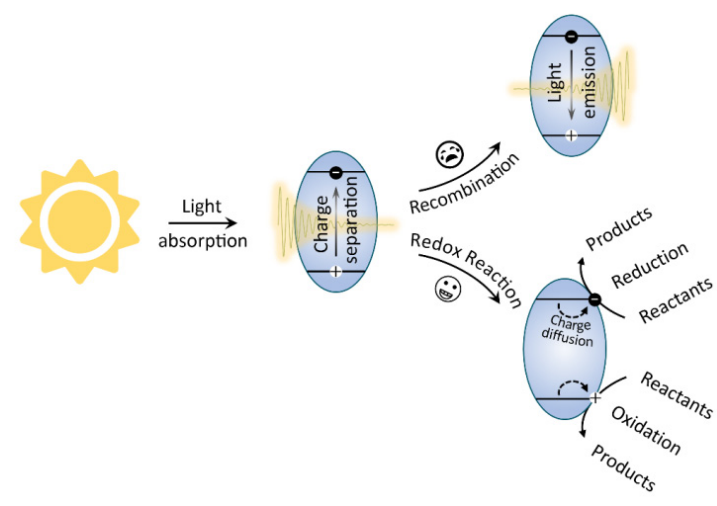

Fig. 2. Schematic illustration of a photocatalytic redox reaction. 
required to prevent their recombination. A rational way to achieve this is providing lower energy level to accommodate the excited electrons or holes. When two semiconductors with different Fermi levels contact closely, the electrons in the semiconductor with higher Fermi level will flow to the other semiconductor to reduce the total energy of the whole system. Consequently, net charges accumulate at the sides of the contacting interface, which makes the originally higher Fermi level lower and the originally lower Fermi level higher. The net electron flow stops until the electrochemical potential of the two semiconductors equals with each other. Meanwhile, the electronic band of the contacting semiconductor bends over in subject to the movement of Fermi levels, generating different forms of band alignments. Some typical band alignments are shown in Fig. 3 with the possibility and pathway of recombination. Among the conventional heterojunctions, the type II heterojunction is more favorable for the separation of electron-hole pairs. For type I heterojunction, the photo-generated electrons and holes can transfer to the relatively lower energy levels, respectively. However, they still accumulate in the same material, with a high possibility to recombine. For type III heterojunction, the energy bands of the two contacting semiconductors do not overlap, which is not suitable for the electron-hole separation and the charge transportation. For type II heterojunction, the electrons and holes can transfer to lower energy levels that exist in different materials. Thus, electron-hole pairs can be separated efficiently and participate in the successive redox reactions. Appropriate band overlap that enables electrons and holes to accumulate in different materials is essential for the design of efficient heterojunction photocatalysts.

From the viewpoint of reaction dynamics, the type II heterojunction is not perfect yet, since it accumulates electrons/holes at the relatively lower energy levels, which means reduced potential and thus weaker reducing/oxidizing ability of the electrons/holes. It would be preferred if the photogenerated electrons and holes can stay at the higher energy level and participate in following redox reactions. The S-scheme pathway provides a strategy to design heterojunctions with full redox potential. The band structure of a S-scheme heterojunction is
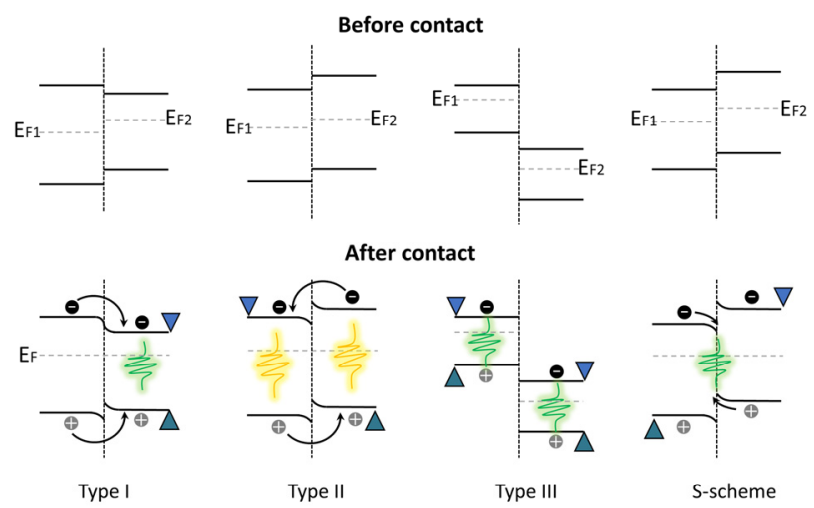

Possibility of recombination

low high

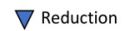

$\triangle$ Oxidation

Fig. 3. Schematic illustration of the band structure of typical conventional heterojunctions and S-scheme heterojunction. shown in Fig. 3. Compared with the type II heterojunction, the band structure of S-scheme heterojunction is similar. However, the recombination pathway in S-scheme heterojunction is different. A S-scheme heterojunction is composed by a reduction-type photocatalyst semiconductor and an oxidation-type photocatalyst semiconductor. To balance the Fermi level of the contacting semiconductors, an internal field is established which drives the photogenerated electrons to flow from the conduction band of the oxidation-type semiconductor to the valence band of the reduction-type semiconductor, consuming the corresponding photogenerated holes. As a result, electrons and holes locating at the lower energy levels are more likely to recombine, leaving the relatively useful electrons and holes with higher potential toward redox reactions. Hence, the S-scheme heterojunction can separate electron-hole pairs and retain full redox potential at the same time.

Besides electron-hole separation through providing lower energy levels, which is driven inherently by electrochemical potential, electrical fields can also behave as a driving force that facilitates the electron-hole separation. For example, an internal electrical field can be built in a PN heterojunction, as shown in Fig. 4. The holes in the $\mathrm{p}$ zone will diffuse to the $\mathrm{n}$ zone until the Fermi level equals with each other, leaving net negative charges in the $\mathrm{p}$ zone. Conversely, there are net positive charges accumulating in the $n$ zone. Therefore, an internal field is formed pointing from the $\mathrm{n}$ zone to the $\mathrm{p}$ zone. Under illumination, the photogenerated electrons and holes will move oppositely driven by the internal electrical field and separate from each other.

Fast separation of photogenerated electron-hole pairs is essential but not sufficient to achieve high-performance photocatalysts. For example, it is important to transfer the separated electrons and holes to the surface of the photocatalyst quickly and timely, otherwise they would recombine instead of participating in reactions. A high electrical conductivity can facilitate the charge transportation. However, most semiconductors do not possess a satisfying electrical conductivity. In this consideration, combining semiconductors with highly conductive materials of large work function becomes the reasonable choice. Graphene, which possesses a conductivity of $20000 \mathrm{~cm}^{2}$ $\mathrm{V}^{-1} \mathrm{~s}^{-1}$ and large work function at room temperature [59], is an ideal material coupling with semiconductors to form the semiconductor-graphene heterojunction. Not only the high conductivity and large work function, its large specific surface area also can facilitate the photocatalytic activity. Benefitting from this type of heterojunction, the photogenerated electrons can

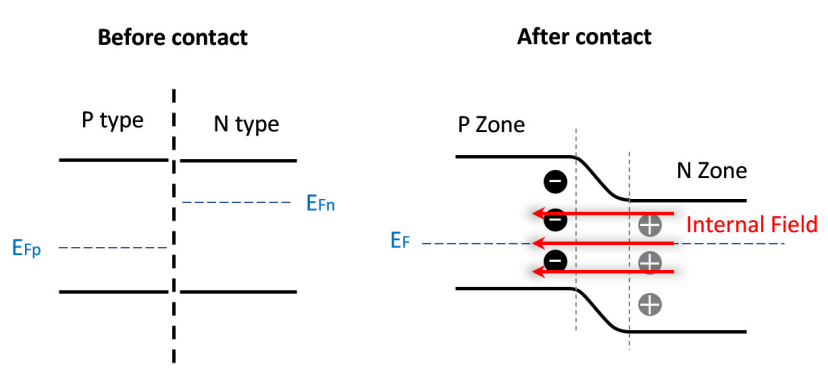

Fig. 4. Schematic illustration of the internal field of a PN heterojunction. 
(a)

EF

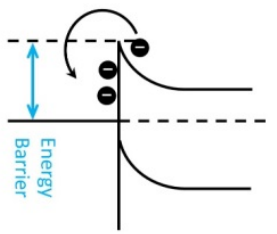

N-type Semiconductor

(b)

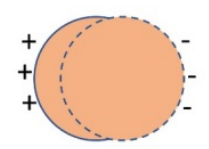

(c)

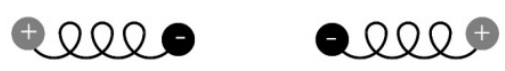

Fig. 5. (a) Band structure of Schottky heterojunction; (b) Illustration of the oscillation of electrons in a metal particle; (c) Harmonic model to describe the plasmon resonance.

be transferred quickly to and accumulate on the graphene surface, where redox reactions occur.

Combining a semiconductor with a metal can form the Schottky heterojunction. Usually, it is required that the metal's work function should be lower than the semiconductor's Fermi level. In this way, after contacting the metal with the semiconductor intimately, the electrons in the semiconductor would flow to the metal due to the lower Fermi level, leaving the positive ions. An electrical field is then formed pointing form the semiconductor to the metal, aligning the band of the semiconductor downwards until the Fermi level equals. The band structure of representative Schottky heterojunctions are shown in Fig. 5(a). Due to the band alignment of the contacting metal and semiconductor, an energy barrier is established with a barrier height determined by the difference of the corresponding work functions. The energy barrier steers the flow of charge carriers that are photogenerated in the semiconductor. The metal serves as a sink for the photogenerated electrons or holes when forming a Schottky junction with a n-type or p-type semiconductor, respectively. Under illumination, the Schottky barrier can prohibit the backflow of photogenerated electrons or holes from metal to semiconductor, achieving efficient unidirectional transfer of charge carriers across the interface and thus preventing the recombination of electron-hole pairs in the semiconductor. Other than the Schottky heterojunction, the combination with metals can also benefit the transportation of electrons to the surface for reactions. Combining with metals can additionally improve the light absorption, which is of equal importance for the photocatalytic efficiency. Particularly, surface plasmon resonance (SPR) has been proposed to enhance the light absorption of photocatalysts. Surface plasmons are the collective movement of the free electrons in metals, as shown in Fig. 5(b) and (c). The surface plasmons act as oscillators interacting with driving electromagnetic waves. The excitation of surface plasmons could largely increase the light-absorption cross-section of the structure, thus promoting the light harvesting. In addition, the plasmonic effect can generate "hot electrons" that can participate in the redox reaction.

To summarize this section, the basic principle to build an efficient photocatalyst based on heterojunctions is to find the appropriate interactions that can separate the photogenerated electron-hole pairs. For example, in type II or Schottky heterojunctions, the flow of electrons/holes to lower energy levels is actually driven by the principle of minimum energy, or we can say the second law of thermodynamics. In PN heterojunction and S-scheme heterojunction, the interaction that separates the electrons and holes is the internal electric field. A table that summarizes the similarity and difference of various heterojunctions is shown in Table 1.

\section{Construction of different types of heterojunctions}

\subsection{Type II heterojunctions}

Tremendous efforts have been dedicated to the development of type II heterojunction photocatalysts due to their effectiveness to separate the photogenerated electron-hole pairs. Lots of type II heterojunctions were designed and prepared, such as $\mathrm{WO}_{3} / \mathrm{TiO}_{2}$ [60], $\mathrm{NiO} / \mathrm{TiO}_{2}$ [61], $\mathrm{CsPbBrCl}_{2} / \mathrm{g}-\mathrm{C}_{3} \mathrm{~N}_{4}$ [62], $\mathrm{CdS} / \mathrm{ZnSe}$ [63], $\mathrm{SnO}_{x} / \mathrm{Zn}_{2} \mathrm{SnO}_{4}$ [64], $\mathrm{CuSbSe}_{2} / \mathrm{TiO}_{2}$ [65] and so on, as compared in Table 2.

Most recently, Wang et al. constructed a type II g- $\mathrm{C}_{3} \mathrm{~N}_{4} / \mathrm{ZnTe}$ heterojunction for the photosynthesis of ethanol by reducing $\mathrm{CO}_{2}$ [68]. Usually, the reduction of $\mathrm{CO}_{2}$ to ethanol (a $\mathrm{C}_{2}$ product) is limited due to the rate-limiting step of C-C coupling. ZnTe is a promising photocatalytic material with high selectivity of reducing $\mathrm{CO}_{2}$ to $\mathrm{CO}$, while g- $\mathrm{C}_{3} \mathrm{~N}_{4}$ can facilitate the $\mathrm{C}_{2}$ production because of the abundant pyridinic $\mathrm{N}$ sites, which are crucial for $\mathrm{CO}^{*}$ dimerization and ethanol formation. By the combination of $\mathrm{ZnTe}$ and $\mathrm{g}-\mathrm{C}_{3} \mathrm{~N}_{4}$, the authors reported an impressive ethanol generation rate of $17.1 \mu \mathrm{mol} \mathrm{cm}-2 \mathrm{~h}^{-1}$ at $-1.1 \mathrm{~V}$ vs. $\mathrm{Ag} / \mathrm{AgCl}$, which is much better than that of separated $g-\mathrm{C}_{3} \mathrm{~N}_{4}$ and $\mathrm{ZnTe}$ (Fig. 6). The formation of the $\mathrm{g}-\mathrm{C}_{3} \mathrm{~N}_{4} / \mathrm{ZnTe}$ heterojunction not only boosted the separation of photogenerated electron and holes, but also accelerated the transportation of electrons from $\mathrm{ZnTe}$ to $\mathrm{g}-\mathrm{C}_{3} \mathrm{~N}_{4}$ driving by the built internal field. The g- $\mathrm{C}_{3} \mathrm{~N}_{4} / \mathrm{ZnTe}-1-2$ sample exhibits the highest $\mathrm{C}_{2} \mathrm{H}_{5} \mathrm{OH}$ genera-

Table 1

Similarity and difference of various heterojunctions.

\begin{tabular}{lcc}
\hline Heterojunctions & Similarity & Difference \\
Type II and S-scheme heterojunctions & Similar band alignment & Recombination pathway \\
Type II and PN heterojunctions & Similar charge separation pathway & The built-in field is against the charge separation for \\
PN and Schottky heterojunctions & Strong internal field & Type II heterojunction \\
\hline
\end{tabular}


Table 2

Comparison of some recently developed type II heterojunction photocatalysts.

\begin{tabular}{|c|c|c|c|c|}
\hline Heterojunction & Application & Performance & Year & Ref. \\
\hline $\mathrm{WO}_{3} / \mathrm{TiO}_{2}$ & Stearic acid degradation & 14 times higher than pure $\mathrm{TiO}_{2}$ & 2017 & [60] \\
\hline $\mathrm{NiO} / \mathrm{TiO}_{2}$ & $\mathrm{H}_{2}$ generation & 22 times greater than $\mathrm{TiO}_{2}$ & 2018 & [61] \\
\hline $\mathrm{CsPbBrCl}_{2} / \mathrm{g}-\mathrm{C}_{3} \mathrm{~N}_{4}$ & Organic effluents degradation & Degrading $94 \%$ of Eosin B dye within $120 \mathrm{~min}$ & 2019 & [62] \\
\hline $\mathrm{CdS} / \mathrm{ZnSe}$ & Water splitting & Higher carrier mobility & 2018 & [63] \\
\hline $\mathrm{SnO}_{x} / \mathrm{Zn}_{2} \mathrm{SnO}_{4}$ & Degradation of methyl orange & Complete decolorization in $30 \mathrm{~min}$ & 2017 & {$[64]$} \\
\hline $\mathrm{CuSbSe}_{2} / \mathrm{TiO}_{2}$ & Degradation of organic dyes & $21.08 \%$ increase in the degradation efficiency than $\mathrm{TiO}_{2}$ & 2019 & {$[65]$} \\
\hline $\mathrm{WO}_{3} / \mathrm{BiOBr}$ & Oxidation of amine to imine & 2 times higher than $\mathrm{WO}_{3}$ & 2020 & {$[66]$} \\
\hline $\mathrm{ZnO} / \mathrm{Ag}_{2} \mathrm{~S}$ & Anti-bacteria & Significant antibacterial activity & 2020 & [67] \\
\hline $\mathrm{g}-\mathrm{C}_{3} \mathrm{~N}_{4} / \mathrm{ZnTe}$ & Photosynthesis of ethanol & Generation rate of $17.1 \mu \mathrm{mol} \mathrm{cm}{ }^{-2} \mathrm{~h}^{-1}$ (at $-1.1 \mathrm{~V}$ vs. $\mathrm{Ag} / \mathrm{AgCl}$ ) & 2019 & {$[68]$} \\
\hline $\mathrm{I}-\mathrm{BiOCl} / \mathrm{I}-\mathrm{BiOBr}$ & Degradation of methyl orange & 7 times than $\mathrm{BiOBr}$ & 2017 & [69] \\
\hline $\mathrm{La}_{2} \mathrm{Ti}_{2} \mathrm{O}_{7} / \mathrm{In}_{2} \mathrm{~S}_{3}$ & $\mathrm{H}_{2}$ generation & 18 times higher than physical mixtures of $\mathrm{La}_{2} \mathrm{Ti}_{2} \mathrm{O}_{7}$ and $\operatorname{In}_{2} \mathrm{~S}_{3}$ & 2019 & {$[70]$} \\
\hline $\mathrm{BiVO}_{4} / \mathrm{WO}_{3}$ & Photoanode & 2.15 times enhancement than $\mathrm{WO}_{3}$ & 2016 & {$[71]$} \\
\hline $\mathrm{Pt} / \mathrm{TiO}_{2} / \mathrm{CdS} / \mathrm{Co}_{3} \mathrm{O}_{4}$ & $\mathrm{H}_{2}$ generation & A generation rate of $2000 \mu \mathrm{mol} \mathrm{g}{ }^{-1} \mathrm{~h}^{-1}$ & 2018 & {$[72]$} \\
\hline $\mathrm{VO}_{2} / \mathrm{CuWO}_{4}$ & Degradation of azure II & Degrading $83.8 \%$ in $80 \mathrm{~min}$ & 2018 & {$[73]$} \\
\hline $\mathrm{ZnS} / \mathrm{g}-\mathrm{C}_{3} \mathrm{~N}_{4}$ & MB degradation & 2.6 times better compared to bare $\mathrm{g}-\mathrm{C}_{3} \mathrm{~N}_{4}$ & 2017 & [74] \\
\hline $\mathrm{Cu}_{2} \mathrm{O} / \mathrm{g}-\mathrm{C}_{3} \mathrm{~N}_{4}$ & $\mathrm{H}_{2}$ generation & 4 times higher than pure $\mathrm{g}-\mathrm{C}_{3} \mathrm{~N}_{4}$ & 2017 & {$[75]$} \\
\hline $\mathrm{CuS} / \mathrm{BiFeO}_{3}$ & Degradation of alachlor & $95 \%$ degradation within $1 \mathrm{~h}$ & 2018 & [76] \\
\hline $\mathrm{Cu}_{2} \mathrm{O} / \mathrm{SnO}_{2}$ & RhB degradation & 2-fold higher than individual $\mathrm{SnO}_{2}$ & 2016 & {$[77]$} \\
\hline S/CdS & $\mathrm{H}_{2}$ generation & $8.14 \mathrm{mmol} \mathrm{h}^{-1}$ & 2017 & [78] \\
\hline $\mathrm{Mn}_{3} \mathrm{O}_{4} / \mathrm{MnO}_{2}$ & MB degradation & 93.5\% degradation within $1 \mathrm{~h}$ & 2017 & [79] \\
\hline $\mathrm{SnS}_{2} / \mathrm{H}-\mathrm{TiO}_{2} / \mathrm{Ti}$ & $\mathrm{H}_{2}$ generation & 70 times higher than $\mathrm{SnS}_{2} / \mathrm{TiO}_{2} / \mathrm{Ti}$ & 2019 & {$[80]$} \\
\hline $\mathrm{TiO}_{2} / \mathrm{CdIn}_{2} \mathrm{~S}_{4}$ & $\mathrm{H}_{2}$ generation & 5.5 times higher than bare $\mathrm{TiO}_{2}$ & 2018 & [81] \\
\hline $\mathrm{IO} / \mathrm{CdS}$ & Degradation of xylenol blue & $97.6 \%$ degradation within $3 \mathrm{~h}$ & 2019 & {$[82]$} \\
\hline g- $\mathrm{C}_{3} \mathrm{~N}_{4} / \mathrm{P} 25$ & $\mathrm{H}_{2}$ generation & 24.5 times higher than pure $\mathrm{g}-\mathrm{C}_{3} \mathrm{~N}_{4}$ & 2019 & [83] \\
\hline $\mathrm{ZnIn}_{2} \mathrm{~S}_{4} / \mathrm{BiPO}_{4}$ & TC degradation & $84 \%$ degradation within $80 \mathrm{~min}$ & 2019 & [84] \\
\hline $\mathrm{Bi}_{2} \mathrm{SiO}_{5} / \mathrm{BiPO}_{4}$ & Phenol degradation & 4.36 timed higher than $\mathrm{Bi}_{2} \mathrm{SiO}_{5}$ & 2018 & [85] \\
\hline $\mathrm{g}-\mathrm{C}_{3} \mathrm{~N}_{4} / \mathrm{Nb}_{2} \mathrm{O}_{5}$ & RhB degradation & 9.4 times higher than $\mathrm{Nb}_{2} \mathrm{O}_{5}$ & 2017 & [86] \\
\hline
\end{tabular}

tion rate, along with considerable amount of side product of $\mathrm{C}_{3} \mathrm{H}_{7} \mathrm{OH}$. Further optimization of the mass ratio of $\mathrm{g}-\mathrm{C}_{3} \mathrm{~N}_{4}$ to ZnTe may improve the ethanol selectivity.

Jia et al. [69] proposed a novel strategy to transform type I heterojunction into type II heterojunction. $\mathrm{BiOCl} / \mathrm{BiOBr}$ is originally a type I heterojunction material, which is not suitable for the separation of photogenerated charges. The authors used I- irons as dopants to raise the valence band positions of BiOCl and $\mathrm{BiOBr}$, respectively. The rise of valence band can narrow the bandgap, resulting in more efficient light energy usage. Furthermore, the valence band position of $\mathrm{BiOX}(\mathrm{X}=\mathrm{Cl}, \mathrm{Br})$ can be controlled by the doping amount of $\mathrm{I}$ - irons. Applying this strategy, the valence band position of $\mathrm{I}-\mathrm{BiOBr}$ was successfully aligned below that of $\mathrm{I}-\mathrm{BiOCl}$, reforming the type-II I-BiOCl/I-BiOBr heterojunction (Fig. 7(a)). Several samples with various molar percentage ratios of I-BiOCl to I-BiOBr were prepared and their photocatalytic activity measurements for methyl orange (MO) and phenol removal were carried out. It is found that all the I-BiOCl/I-BiOBr composites exhibited remarkable photocatalytic activity, while the $20 \%$ I-BiOCl sample performs the best, as shown in Fig. 7(b) and (d). The pseudo-first-order rate constant was calculated to analyze the reaction kinetics of MO and phenol degradations, with results shown in Fig. 7(c) and (e). The 20\% I-BiOCl sample possesses the highest kinetics, which accounts the best degradation performance. The doping method, however, could change the inherent properties of the material somehow. The rational con-
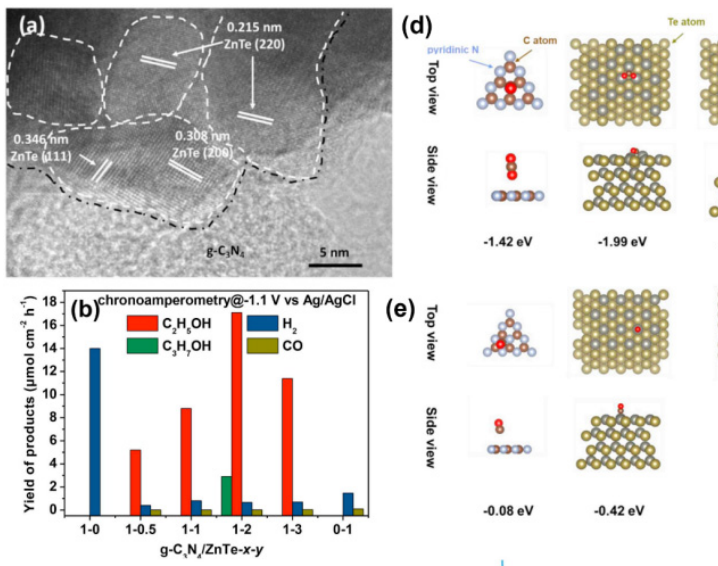

(e) $\frac{g^{2}}{2}$
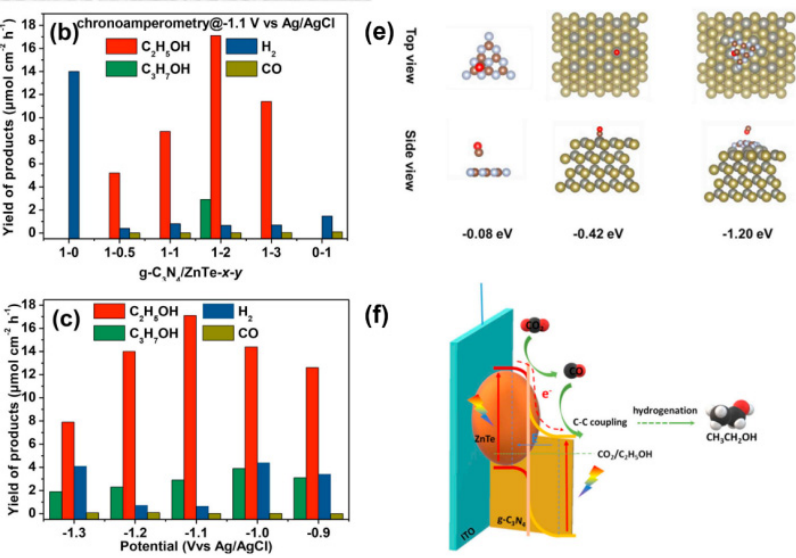

(f)

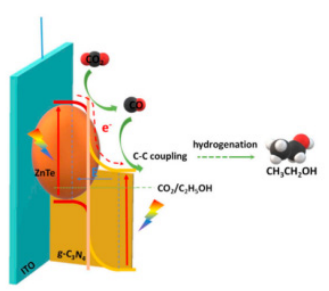

Fig. 6. (a) HRTEM image of $\mathrm{g}-\mathrm{C}_{3} \mathrm{~N}_{4} / \mathrm{ZnTe}$. (b) Products of g- $\mathrm{C}_{3} \mathrm{~N}_{4} / \mathrm{ZnTe}-x-y$ ( $x$ and $y$ represented the mass ratio of $g-\mathrm{C}_{3} \mathrm{~N}_{4}$ and $\mathrm{ZnTe}$ at -1.1 V vs. $\mathrm{Ag} / \mathrm{AgCl}$. (c) Products of g- $\mathrm{C}_{3} \mathrm{~N}_{4} / \mathrm{ZnTe}-1-2$ at various applied potentials. $(\mathrm{d}, \mathrm{e})$ The optimized geometry structures and binding energies for $\mathrm{CO}_{2}$ (d) and $\mathrm{CO}$ (e) adsorption on $\mathrm{g}-\mathrm{C}_{3} \mathrm{~N}_{4}, \mathrm{ZnTe}$, and g- $\mathrm{C}_{3} \mathrm{~N}_{4} / \mathrm{ZnTe}$. (f) Schematic diagram of band configuration and the charge separation at the interface of $g-\mathrm{C}_{3} \mathrm{~N}_{4} / \mathrm{ZnTe}$ heterojunction. (reproduced with permission [68], copyright 2019, Elsevier). 
(a)
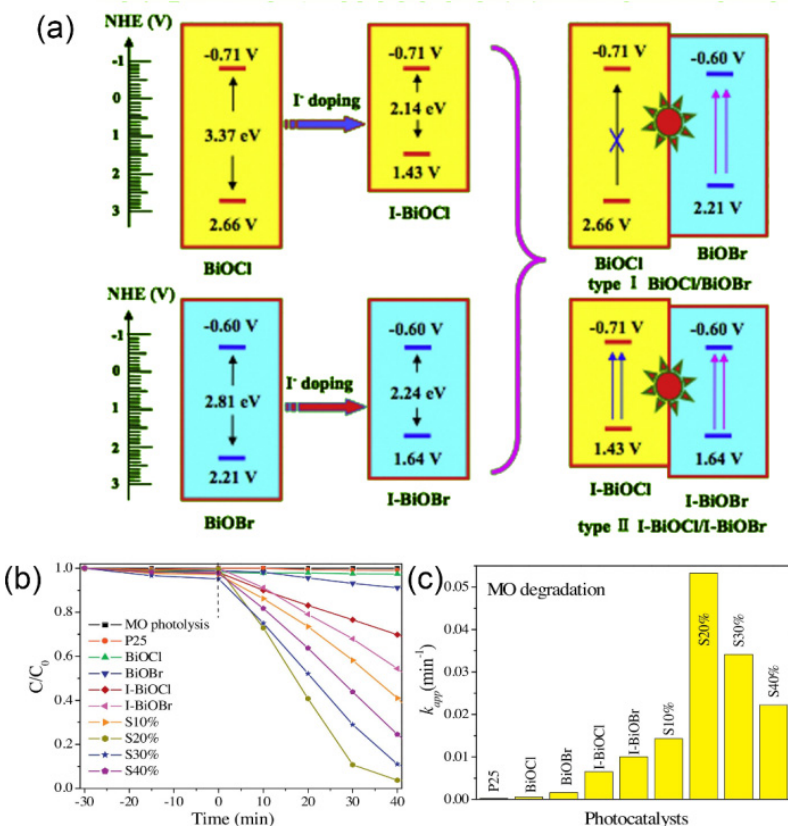

(d)
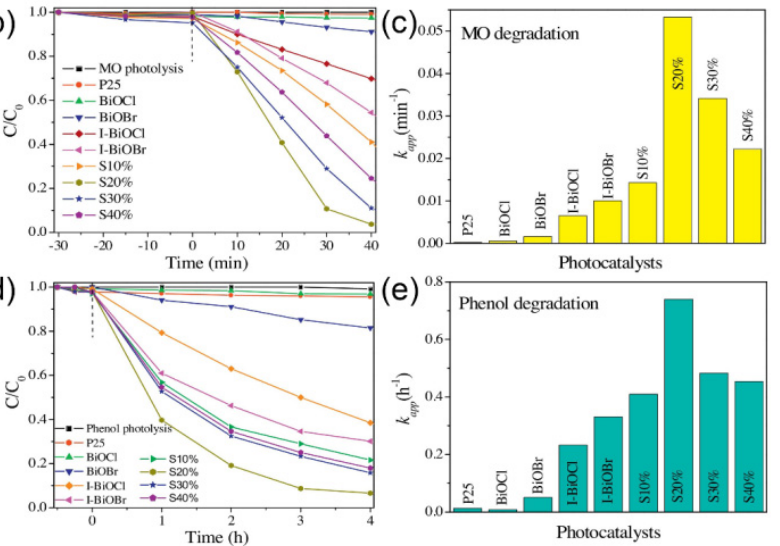

Fig. 7. (a) Band structure of type-II I-BiOCl/I-BiOBr composite. Photocatalytic activities (b,d) and corresponding kapp constant (c,e) of various samples for MO and phenol degradation. (reproduced with permission [69], copyright 2017, Elsevier).

trol of doping type and amount of materials is of vital importance.

Material with multiple type II heterojunctions are also investigated. For example, Tang et al. [87] fabricated a triadic QD@LDH@BiVO 4 (QD: CdTe quantum dots, LDH: Co-based layered double hydroxide) photoanode to highly enhance the photoelectrochemical water oxidation efficiency. The photoanode possesses two sets of consecutive Type-II band alignments, the QD@LDH and the LDH@BiVO To highlight the photocatalytic performance of this special material, $\mathrm{BiVO}_{4}$ without a type II heterojunction structure, and

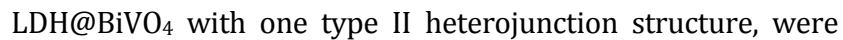
also prepared and their photoactive performance was measured and compared. Experimental results reveled that the photocurrent and the IPCE (incident-photon-to-current con-

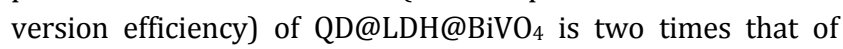

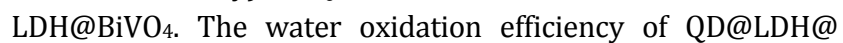
$\mathrm{BiVO}_{4}$ reaches above $90 \%$ at a low potential of $0.5 \mathrm{~V}$ vs RHE, which is superior to most $\mathrm{BiVO}_{4}$-based materials. The outstanding performance is proved to be attributed to the unique band configuration with two consecutive type II band alignments between the ternary components, which greatly improves electron transfer and hole diffusion.

In the past decade, the adoption of $2 \mathrm{D}$ materials also appealed particular interest in the field of photocatalysis, due to (a)

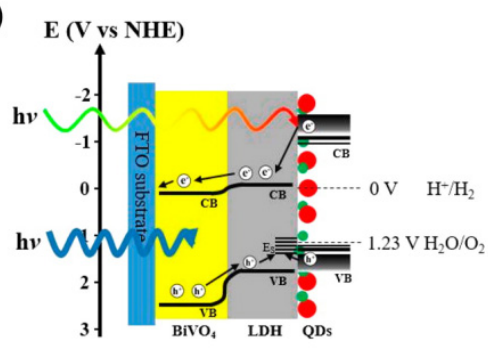

(f)
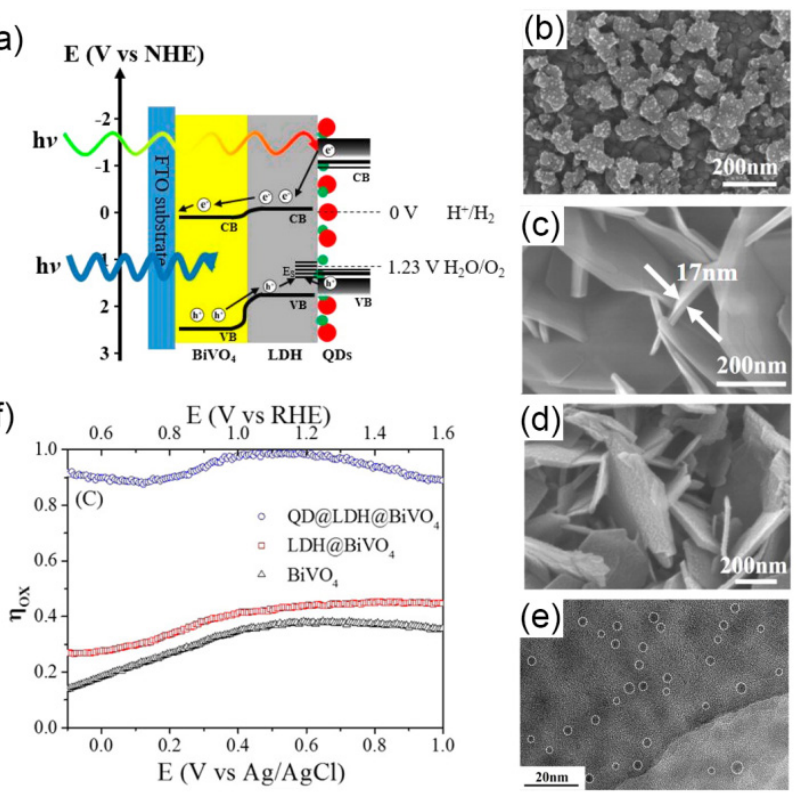

Fig. 8. (a) Band alignment of the QD@LDH@BiVO ${ }_{4}$ (QD: CdTe quantum dots, LDH: Co-based layered double hydroxide) photoanode. (b-d) SEM images of $\mathrm{BiVO}_{4}, \mathrm{LDH}_{\mathrm{B}} @ \mathrm{BiVO}_{4}$ and $\mathrm{QD} @ \mathrm{LDH} @ \mathrm{BiVO}_{4}$, respectively. (e) HRTEM images of QD@LDH@BiVO 4 . (f) Oxidation efficiency of the surface-reaching holes injected into the solution species. (reproduced with permission [87], copyright 2016, American Chemistry Society).

their exotic electrical or optical properties. Because of the 2D nature, they can minimize the distance that photogenerated electrons and holes have to travel until to the surface for redox reactions. Type II heterojunctions based on $2 \mathrm{D}$ materials have been designed and studied as efficient photocatalysts theoretically or experimentally [70,88-90]. For example, Kumar et al. [88] designed $\mathrm{C}_{2} \mathrm{~N} / \mathrm{WS}_{2}$ heterojunction (Fig. 9) theoretically. The heterojunction could facilitate water splitting in three aspects. First, the band gap reduces due to the compounding of the constituent monolayers, enhancing significantly the light absorption. Second, the band edges of the heterostructure satisfies both water oxidation and reduction potential levels.
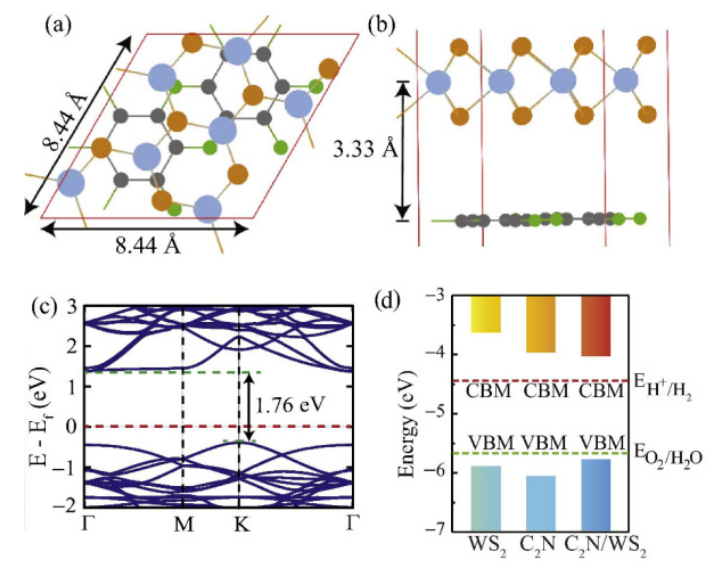

Fig. 9. (a,b) Top and side view of the $\mathrm{C}_{2} \mathrm{~N} / \mathrm{WS}_{2}$ heterojunction. Grey, green, purple and orange colors denote $\mathrm{C}, \mathrm{N}, \mathrm{W}$ and $\mathrm{S}$ atoms, respectively. (c) Band structure of the $\mathrm{C}_{2} \mathrm{~N} / \mathrm{WS}_{2}$ heterojunction. (d) Absolute energy positions of VBM (valence band maxima) and CBM (conduction band minima) for all three structures with respect to vacuum level. (reproduced with permission [88], copyright 2018, Elsevier). 
Third, the band structure of the heterojunction forms a type-II alignment, enabling the transportation of electrons and holes into different $\mathrm{C}_{2} \mathrm{~N}$ and $\mathrm{WS}_{2}$ layers respectively, which prevents the recombination efficiently. In another work, Hua et al. fabricated experimentally a 2D type-II heterojunction $\mathrm{La}_{2} \mathrm{Ti}_{2} \mathrm{O}_{7} / \mathrm{In}_{2} \mathrm{~S}_{3}$ [70] (Fig. 10). Firmly intimate contact of the two layers was realized because of the strong coulomb static force between $\mathrm{La}_{2} \mathrm{Ti}_{2} \mathrm{O}_{7}$ and $\mathrm{In}_{2} \mathrm{~S}_{3}$ due to their inverse Zeta potentials. The strong interaction between the two layers and the type II band structure co-promoted the charge separation, which accounts for the superior photocatalytic activity for hydrogen production. Various heterojunctions with different mass ratios of $\mathrm{La}_{2} \mathrm{Ti}_{2} \mathrm{O}_{7}$ to $\mathrm{In}_{2} \mathrm{~S}_{3}$ were prepared and measured. Experimental results revealed an optimal mass ratio at 7.5:1.0, where the sample demonstrated a hydrogen production rate 3.5 times higher than pristine $\operatorname{In}_{2} \mathrm{~S}_{3}$ and 18 times higher than physical mixtures of $\mathrm{La}_{2} \mathrm{Ti}_{2} \mathrm{O}_{7}$ and $\mathrm{In}_{2} \mathrm{~S}_{3}$.

\subsection{PN heterojunctions}

Although type II heterojunctions can separate photoinduced charges with a high efficiency, it was reported that PN heterojunctions can separate the charges even faster [91], with the aid of internal electric fields. Therefore, PN heterojunctions belong to an important branch of heterojunction-based photocatalysts. Numerous PN heterojunctions have been fabricated and studied, with recent works like $\mathrm{Ag}_{2} \mathrm{O} / \mathrm{Bi}_{2} \mathrm{O}_{2} \mathrm{CO}_{3}$ [92], $\mathrm{Fe}_{2} \mathrm{O}_{3} / \mathrm{BiOI}$ [93], $\mathrm{Cu}_{3} \mathrm{P} / \mathrm{g}-\mathrm{C}_{3} \mathrm{~N}_{4}$ [94], $\mathrm{MoSe}_{2} / \mathrm{Bi}_{2} \mathrm{WO}_{6}$ [95], $\mathrm{ZnO} / \mathrm{MnWO}_{4}$ [96], BiOI/ $\mathrm{BiPO}_{4}$ [97], $\mathrm{Cu}_{2} \mathrm{O} / \mathrm{SnO}_{2}$ [98] and so on. The performance
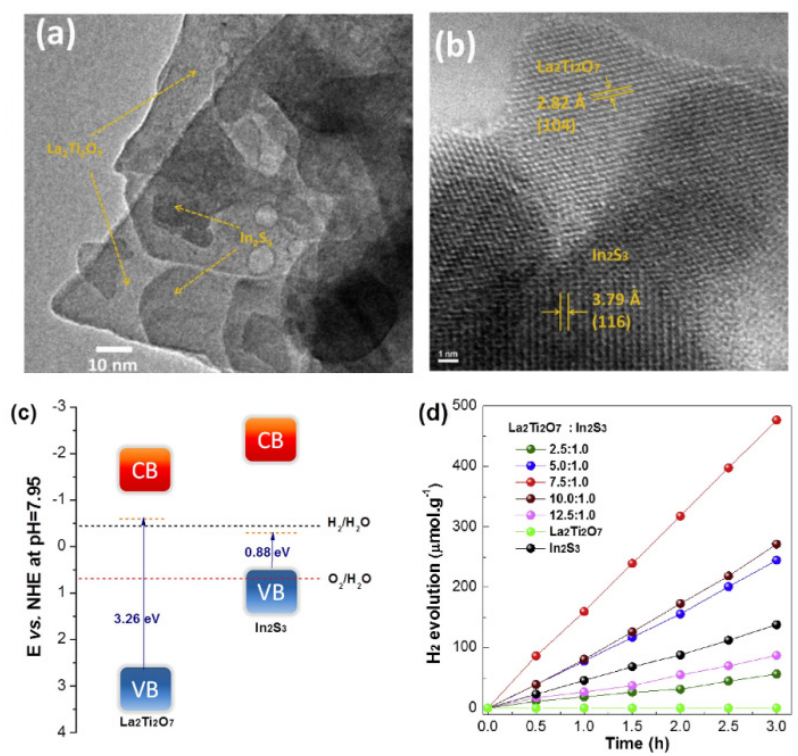

Fig. 10. (a) TEM image of the $\mathrm{La}_{2} \mathrm{Ti}_{2} \mathrm{O}_{7} / \mathrm{In}_{2} \mathrm{~S}_{3}$ heterojunction. (b) HRTEM image of the $\mathrm{La}_{2} \mathrm{Ti}_{2} \mathrm{O}_{7} / \mathrm{In}_{2} \mathrm{~S}_{3}$ heterojunction. (c) Schematic illustration of the band edge positions for both $\mathrm{La}_{2} \mathrm{Ti}_{2} \mathrm{O}_{7}$ and $\mathrm{In}_{2} \mathrm{~S}_{3}$. (reproduced with permission [70], copyright 2019, Elsevier).

of some PN heterojunction photocatalysts are listed in Table 3.

Most recently, Liu et al. [118] prepared the $\mathrm{Cu}_{2-x} \mathrm{Se} / \mathrm{CdS} \mathrm{PN}$ heterojunction composite to improve the degradation rate of Rhodamine $\mathrm{B}(\mathrm{RhB}) . \mathrm{Cu}_{2-x} \mathrm{Se}$ is a p type semiconductor while $\mathrm{CdS}$ is an $\mathrm{n}$ type one (Fig. 11). When the two semiconductors

Table 3

Comparison of some recently developed PN heterojunction photocatalysts.

\begin{tabular}{|c|c|c|c|c|}
\hline Heterojunction & Application & Performance & Year & Ref. \\
\hline $\mathrm{Fe}_{2} \mathrm{O}_{3} / \mathrm{BiOI}$ & RhB degradation & 4.24 times higher than single $\mathrm{BiOI}$ & 2016 & [93] \\
\hline $\mathrm{Cu}_{3} \mathrm{P} / \mathrm{g}-\mathrm{C}_{3} \mathrm{~N}_{4}$ & Hydrogen generation & 95 times higher activity than bare $g-\mathrm{C}_{3} \mathrm{~N}_{4}$ & 2018 & [94] \\
\hline $\mathrm{MoSe}_{2} / \mathrm{Bi}_{2} \mathrm{WO}_{6}$ & Degradation of gas-phase toluene & 7 times higher compared with pure $\mathrm{MoSe}_{2}$ & 2018 & [95] \\
\hline $\mathrm{ZnO} / \mathrm{MnWO}_{4}$ & Degradations of $\mathrm{RhB}, \mathrm{MB}, \mathrm{MO}$ & $\begin{array}{l}22.5,17.7,26.8 \text { times higher than that of the } \mathrm{ZnO} \text { sample in degrada- } \\
\text { tions of } \mathrm{RhB}, \mathrm{MB}, \mathrm{MO}\end{array}$ & 2018 & [96] \\
\hline $\mathrm{BiOI} / \mathrm{BiPO}_{4}$ & Degradation of tetracycline & 1.98 times and 2.46 times higher than $\mathrm{BiOI}$ and $\mathrm{BiPO}_{4}$ & 2019 & [97] \\
\hline $\mathrm{Ag}_{2} \mathrm{~S} / \mathrm{BiVO}_{4}$ & Degradation of tetracycline & $90.2 \%$ degradation efficiency & 2019 & [99] \\
\hline $\mathrm{Ag}_{2} \mathrm{O} / \mathrm{AgNbO}_{3}$ & Degradation of RhB & Degradation efficiency of $95.4 \%$ within 90 min & 2019 & {$[100]$} \\
\hline $\mathrm{MoS}_{2} / \mathrm{MgIn}_{2} \mathrm{~S}_{4}$ & $\mathrm{NH}_{3}$ production & 4 and 7 times higher than bare MoS2 and $\operatorname{MgIn}_{2} S_{4}$ & 2020 & [101] \\
\hline $\mathrm{Bi}_{2} \mathrm{O}_{3} / \mathrm{MoS}_{2}$ & Hydrogen generation & 10 times higher than pure $\mathrm{Bi}_{2} \mathrm{O}_{3}$ and $\mathrm{MoS}_{2}$ & 2020 & [102] \\
\hline $\mathrm{ZnFe}_{2} \mathrm{O}_{4} / \mathrm{SnS}_{2}$ & Degradation of MO & 1.7 times higher than individual $\mathrm{ZnFe}_{2} \mathrm{O}_{4}$ & 2020 & [103] \\
\hline $\mathrm{BiVO}_{4} @ \mathrm{MoS}_{2}$ & Reduction of $\mathrm{Cr}^{6+}$ & $76.5 \% \mathrm{Cr}^{6+}$ reduced within $90 \mathrm{~min}$ & 2016 & [104] \\
\hline $\mathrm{g}-\mathrm{C}_{3} \mathrm{~N}_{4} / \mathrm{Bi}_{4} \mathrm{Ti}_{3} \mathrm{O}_{12}$ & Degradation of acid orange-II & 2.85 times higher than pure $\mathrm{Bi}_{4} \mathrm{Ti}_{3} \mathrm{O}_{12}$ & 2016 & [105] \\
\hline $\mathrm{WO}_{6} / \mathrm{BiOI}$ & Antifouling & 99.99\% P. aeruginosa, E. coli and S. aureus killed within 60 min & 2016 & [106] \\
\hline $\mathrm{BiPO}_{4} / \mathrm{BiOCl}$ & MO degradation & A degradation efficiency of $98 \%$ within 14 min & 2015 & [107] \\
\hline $\mathrm{Ag}_{2} \mathrm{O} / \mathrm{Bi}_{5} \mathrm{O}_{7} \mathrm{I}$ & Degradation of Bisphenol A and phenol & A degradation efficiency of $99.9 \%$ within $40 \mathrm{~min}$ & 2017 & [108] \\
\hline $\mathrm{BiOI} / \mathrm{CeO}_{2}$ & MO degradation & A degradation efficiency of $93.75 \%$ within 50 min & 2017 & [109] \\
\hline $\mathrm{Ag}_{2} \mathrm{O} / \mathrm{TiO}_{2}$ & PNP degradation & 7.7 times higher than $\mathrm{TiO}_{2}$ & 2015 & [110] \\
\hline $\mathrm{CdWO}_{4} / \mathrm{BiOBr}$ & Degradation of RhB & 2.8 times better than $\mathrm{BiOBr}$ & 2016 & [111] \\
\hline $\mathrm{BiPO}_{4} / \mathrm{BiOBr}$ & $o$-Dichlorobenzene removal & A removal efficiency of $53.6 \%$ & 2017 & [112] \\
\hline $\mathrm{CuO} / \mathrm{ZnO}$ & Degradation of RhB and CR & Complete degradation within $60 \mathrm{~min}$ & 2017 & [113] \\
\hline $\mathrm{Ag}_{2} \mathrm{O} / \mathrm{BiOCOOH}$ & Degradation of RhB & $96.8 \%$ degradation within $60 \mathrm{~min}$ & 2017 & [114] \\
\hline $\mathrm{Bi}_{2} \mathrm{Sn}_{2} \mathrm{O}_{7} / \mathrm{Ag}_{2} \mathrm{CrO}_{4}$ & Degradation of RhB, MO and MB & $97.5 \%, 90.4 \%$ and $99.8 \%$ degradation within $120 \mathrm{~min}$, respectively & 2018 & [115] \\
\hline $\mathrm{Co}_{3} \mathrm{O}_{4} / \mathrm{Bi}_{2} \mathrm{O}_{2} \mathrm{CO}_{3}$ & Degradation of MO & $90 \%$ degradation within $150 \mathrm{~min}$ & 2017 & [116] \\
\hline $\mathrm{BiOI} / \mathrm{TiO}_{2}$ & Selective hydroxylation of phenol & A selectivity of $92.1 \%$ & 2018 & [117] \\
\hline
\end{tabular}



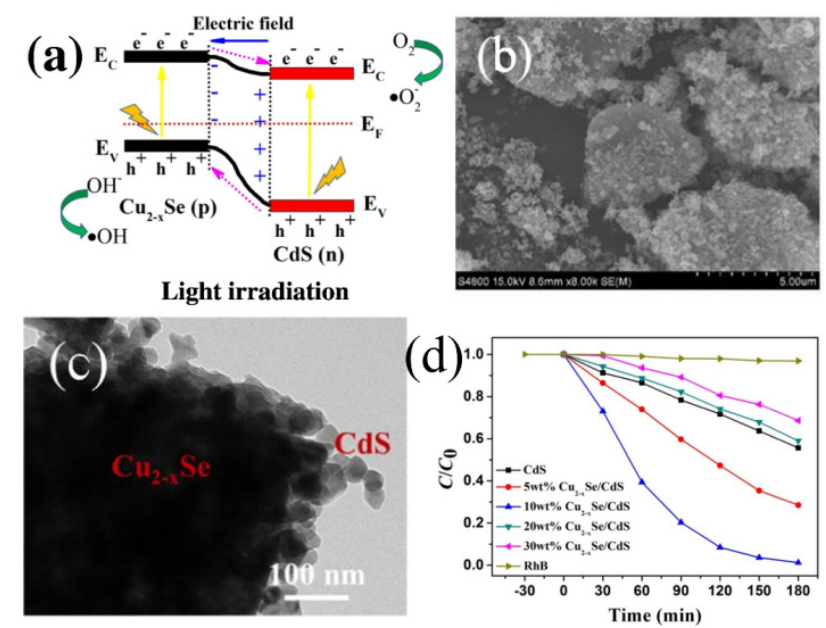

Fig. 11. (a) The charge transfer pathway between $\mathrm{Cu}_{2-x} \mathrm{Se}$ and $\mathrm{CdS}$ under illumination. (b,c) SEM and TEM images of $10 \mathrm{wt} \% \mathrm{Cu}_{2-x} \mathrm{Se} / \mathrm{CdS}$ composite. (d) Photocatalytic performance of $\mathrm{CdS}$ and different ratios of $\mathrm{Cu}_{2-x} \mathrm{Se} / \mathrm{CdS}$ composites. (reproduced with permission [118], copyright 2019, Elsevier).

hybrid, an internal electric field is established pointing from $\mathrm{CdS}$ to the $\mathrm{Cu}_{2-x} \mathrm{Se}$ side. Samples with various mass ratios of $\mathrm{Cu}_{2-x} \mathrm{Se}$ were prepared. It was found that the $10 \mathrm{wt} \%$ $\mathrm{Cu}_{2-x} \mathrm{Se} / \mathrm{CdS}$ composite performed the best in $\mathrm{RhB}$ degradation process with a superior rate, which was almost 8 times higher than that of pure CdS. Further analysis revealed that the boosted photocatalytic efficiency could be mainly ascribed to the formation of a PN heterojunction at the interface of $\mathrm{Cu}_{2-x} \mathrm{Se} / \mathrm{CdS}$ material, which accelerated the charge separation and thus reduced the recombination possibility in the photocatalyst. In this work, the $\mathrm{Cu}_{2-x} \mathrm{Se} / \mathrm{CdS}$ heterojunction was prepared by facile a hydrothermal method. It is expected that the interaction between $\mathrm{Cu}_{2-x} \mathrm{Se}$ and $\mathrm{CdS}$ could be improved by optimizing the preparation process, which may yield stronger internal field and higher efficiency.

Lu et al. [119] proposed a strategy that PN heterojunction could be constructed through a phase transition method. In this work, $\mathrm{Bi}_{2} \mathrm{O}_{3} / \mathrm{Bi}_{2} \mathrm{SiO}_{5}$ photocatalysts were prepared by a facile one-step calcination process. Specifically, $\alpha-\mathrm{Bi}_{2} \mathrm{O}_{3}$ can be obtained by keeping $\mathrm{Bi}\left(\mathrm{NO}_{3}\right)_{3}$ powder at a temperature of $600{ }^{\circ} \mathrm{C}$ for $4 \mathrm{~h}$. However, if nano-sized $\mathrm{SiO}_{2}$ powder was mixed to the $\mathrm{Bi}\left(\mathrm{NO}_{3}\right)_{3}$ powder, $\alpha-\mathrm{Bi}_{2} \mathrm{O}_{3}$ would transform to its counterpart phase $\mathrm{\beta}_{-} \mathrm{Bi}_{2} \mathrm{O}_{3}$ under the same calcination condition (Fig. 12). Also, $\mathrm{Bi}_{2} \mathrm{SiO}_{5}$ were generated with the addition of nano-sized $\mathrm{SiO}_{2}$ powder. The emergence of the usual metastable $\beta-\mathrm{Bi}_{2} \mathrm{O}_{3}$ can be attributed to the suppression of heat release of $\mathrm{Bi}\left(\mathrm{NO}_{3}\right)_{3}$, due to the formation of $\mathrm{Bi}_{2} \mathrm{SiO}_{5}$ coated on the surface. Typically, $\mathrm{Bi}_{2} \mathrm{SiO}_{5}$ is an $\mathrm{n}$ type semiconductor while $\beta-\mathrm{Bi}_{2} \mathrm{O}_{3}$ is $\mathrm{p}$-type one. Thus, their combination resulted in the formation of a PN heterojunction, which drove the separation of photogenerated electrons and holes. Therefore, with the enhanced charge separation, the larger specific surface area and the improved light response range, the $\mathrm{Bi}_{2} \mathrm{O}_{3} / \mathrm{Bi}_{2} \mathrm{SiO}_{5}$ heterojunction exhibited great enhancement of photocatalytic activity compared to $\alpha-\mathrm{Bi}_{2} \mathrm{O}_{3}$

Novel 2D/2D PN heterojunctions were also synthesized. For example, Ao et al. [120] prepared a 2D/2D $\mathrm{BiOBr} / \mathrm{La}_{2} \mathrm{Ti}_{2} \mathrm{O}_{7}$ photocatalyst to enhance the photocatalytic degradation of Rhodamine B and phenol under both UV and visible light irradiation. BiOBr can be excited by both UV and visible light, while $\mathrm{La}_{2} \mathrm{Ti}_{2} \mathrm{O}_{7}$ can be excite only by UV light due to the larger bandgap. In this work, lamellar $\mathrm{La}_{2} \mathrm{Ti}_{2} \mathrm{O}_{7}$ were first prepared by a hydrothermal method. Then, smaller BiOBr nanoplates were dispersed on the larger $\mathrm{La}_{2} \mathrm{Ti}_{2} \mathrm{O}_{7}$ nanosheets through a simple an in-situ growth method (Fig. 13(a)). Thus, tremendous PN heterojunctions were formed at the interfaces of the two 2D materials, which not only accelerated the photogenerated electrons to transfer to $\mathrm{La}_{2} \mathrm{Ti}_{2} \mathrm{O}_{7}$ under visible light, but also accelerated the holes to transfer to $\mathrm{BiOBr}$ under UV light. Consequently, the $\mathrm{BiOBr} / \mathrm{La}_{2} \mathrm{Ti}_{2} \mathrm{O}_{7}$ compound could decompose contaminates much faster compared to pristine $\mathrm{La}_{2} \mathrm{Ti}_{2} \mathrm{O}_{7}$.

\subsection{Schottky heterojunctions}

Photocatalysts based on semiconductor/metal Schottky heterojunctions have been proposed and prepared by different groups [121-134], with typical examples shown in Table 4. Recently, Zhong et al. [135] constructed a CdS/Cd Schottky junction photocatalyst to facilitate the hydrogen production from water splitting. Ultrafast laser technique was adopted to fabricate the novel material. Specifically, metallic Cd clusters could be generated in situ on the surface of $\mathrm{CdS}$ after the laser treatment, forming the Schottky heterojunction (Fig. 14). Due to the generation of $\mathrm{Cd}$ clusters, the photocatalytic hydrogen yield of CdS/Cd was 40 times compared to that of pure CdS in
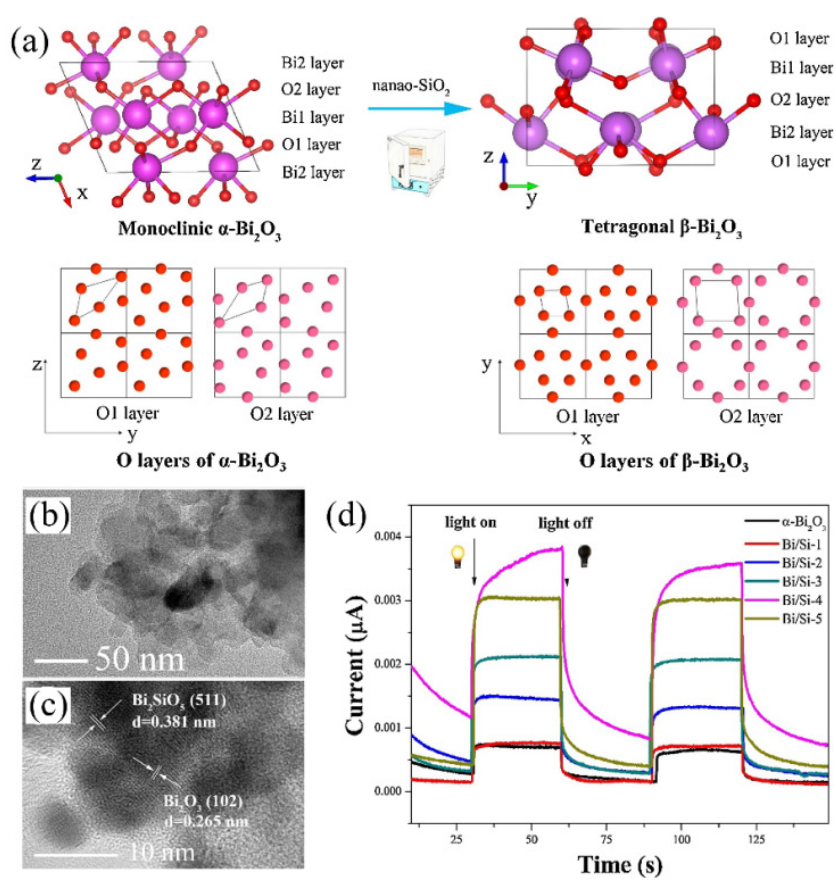

Fig. 12. (a) The schematic transformation from $\alpha-\mathrm{Bi}_{2} \mathrm{O}_{3}$ to the $\beta-\mathrm{Bi}_{2} \mathrm{O}_{3}$. (b,c) TEM and HRTEM images of $\mathrm{Bi}_{2} \mathrm{O}_{3} / \mathrm{Bi}_{2} \mathrm{SiO}_{5}$ heterojunction. (d) Photocurrent responses of $\alpha-\mathrm{Bi}_{2} \mathrm{O}_{3}$ and $\mathrm{Bi}_{2} \mathrm{O}_{3} / \mathrm{Bi}_{2} \mathrm{SiO}_{5}$ heterojunctions. The products with the $\mathrm{SiO}_{2}$ mass ratio of $1 \%, 5 \%, 10 \%, 15 \%$ and $20 \%$ were denoted as $\mathrm{BiSi}-1, \mathrm{BiSi}-2$, BiSi-3, BiSi-4 and BiSi-5, respectively. (reproduced with permission [119], copyright 2018, Elsevier). 

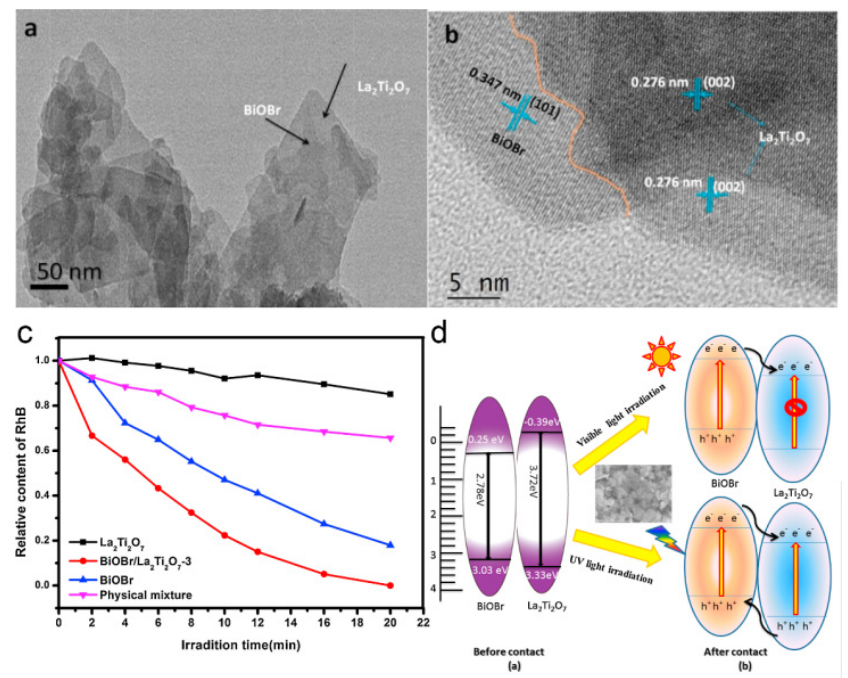

Fig. 13. (a,b) TEM and HRTEM images of the $\mathrm{BiOBr} / \mathrm{La}_{2} \mathrm{Ti}_{2} \mathrm{O}_{7}$ heterojunction. (c) Photocatalytic activity of various samples for RhB degradation. (d) Schematic diagram of the possible photocatalytic mechanism over $\mathrm{BiOBr} / \mathrm{La}_{2} \mathrm{Ti}_{2} \mathrm{O}_{7}$ under both UV and visible light irradiation. (reproduced with permission [120], copyright 2016, Elsevier).

four hours. The improved performance was attributed to three aspects. First, the Cd clusters served as electron skins to accept the exited electrons via the Schottky heterojunction. Second, the CdS/Cd exhibited stronger adsorption capacity for sacrificial agents, promoting the consumption of holes. Third, the narrowed band gap benefited much stronger light absorption. Although the pulse laser induced the Schottky heterojunctions, the yield of Cd clusters is relatively low. Operations that improve the yield of Cd clusters, such as larger optical power, are expected to further improve the photocatalytic performance.

$\mathrm{Gu}$ et al. [125] designed dual $\mathrm{RuO}_{2} / \mathrm{TiO}_{2}$ type II heterojunction and $\mathrm{Ru} / \mathrm{TiO}_{2}$ Schottky heterojunction to enhance the photocatalytic full water splitting. $\mathrm{TiO}_{2}$ nanobelts (NBs) were modified with metallic $\mathrm{Ru}$ and $\mathrm{RuO}_{2}$ nanoparticles through a wet-impregnation reduction method, as illustrated in Fig. 15. The band structure analysis revealed the formation of a Schottky junction at the $\mathrm{Ru} / \mathrm{TiO}_{2}$ interface and a type II heterojunction at the $\mathrm{RuO}_{2} / \mathrm{TiO}_{2}$ interface. The $\mathrm{RuO}_{2} / \mathrm{TiO}_{2}$ heterojunction can improve the transfer of the photogenerated holes from $\mathrm{TiO}_{2}$ to $\mathrm{RuO}_{2}$ to produce $\mathrm{O}_{2}$, while the $\mathrm{Ru} / \mathrm{TiO}_{2}$ Schottky heterojunction can promote the transfer of photogenerated electrons from $\mathrm{TiO}_{2} \mathrm{NBs}$ to the $\mathrm{Ru}$ for proton reduction into $\mathrm{H}_{2}$.

In addition to the formation of the Schottky heterojunction, the combination of a semiconductor and a metal could also benefit from the plasmon effect with proper metal size [149-152]. Xiao et al. [153] prepared metal-organic framework (MOF) composites to enhance the photocatalytic activity by Integrating plasmonic effects and Schottky junctions. Utilizing a semiconductor-like MOF MIL-125, a Pt@MIL-125/Au catalyst was prepared, which integrated the surface plasmon effect of $\mathrm{Au}$ nanorods with a Pt/MOF Schottky heterojunction. The plasmonic excitation effectively extended the light absorption

Table 4

Comparison of some recently developed Schottky heterojunction photocatalysts.

\begin{tabular}{|c|c|c|c|c|}
\hline Heterojunction & Application & Performance & Year & Ref. \\
\hline $\mathrm{Ru} / \mathrm{TiO}_{2}$ & Water splitting & $\mathrm{H}_{2}$ evolution rate of $40.2 \mu \mathrm{mol} \mathrm{h}^{-1} \mathrm{~g}^{-1}$ & 2016 & {$[125]$} \\
\hline $\mathrm{Au} / \mathrm{Cu}_{2} \mathrm{O}$ & MO degradation & 1.2 times higher than pure $\mathrm{Cu} 20$ microcubes & 2016 & [127] \\
\hline $\mathrm{TiO}_{2} / \mathrm{NC}-\mathrm{Ru}$ & Oxidation of benzyl alcohol & $99 \%$ selectivity & 2019 & [128] \\
\hline $\mathrm{TaON} / \mathrm{Ni}$ & Reduction of $\mathrm{CO}_{2}$ to $\mathrm{CH}_{4}$ & 5.1 times higher than pristine $\mathrm{TaON}$ & 2019 & [129] \\
\hline $\mathrm{Bi}_{2} \mathrm{MoO}_{6} / \mathrm{Ti}_{3} \mathrm{C}_{2}$ & Molecular oxygen activation & 5.6 times higher than pristine samples & 2020 & {$[130]$} \\
\hline $\mathrm{CoSe}_{2} / \mathrm{CdS}_{0.95} \mathrm{Se}_{0.05}$ & $\mathrm{H}_{2}$ evolution & 66 times higher than $\mathrm{CdS}$ & 2020 & [131] \\
\hline $\mathrm{Co}_{1.4} \mathrm{Ni}_{0.6} \mathrm{P}$ & $\mathrm{H}_{2}$ evolution & $\mathrm{H}_{2}$ evolution rate of $405 \mu \mathrm{mol} \mathrm{h} \mathrm{h}^{-1} \mathrm{~g}^{-1}$ & 2020 & {$[132]$} \\
\hline $\mathrm{PdAg} / \mathrm{g}-\mathrm{C}_{3} \mathrm{~N}_{4}$ & Dehydrogenation of formic acid & TOF of $420 \mathrm{~h}^{-1}$ & 2019 & [133] \\
\hline $\mathrm{CdS} / \mathrm{Ti}_{3} \mathrm{C}_{2}$ & $\mathrm{H}_{2}$ evolution & 7 times higher than CdS & 2020 & {$[134]$} \\
\hline $\mathrm{CdS} / \mathrm{Cd}$ & $\mathrm{H}_{2}$ evolution & 40 times compared to pure $\mathrm{CdS}$ & 2019 & [135] \\
\hline $\mathrm{Pd} / \mathrm{SiC}$ & $\begin{array}{l}\text { Coupling of iodobenezene and phe- } \\
\text { nylboronic acid }\end{array}$ & A high turnover frequency of $1053 \mathrm{~h}^{-1}$ and a selectivity of nearly $100 \%$ & 2015 & [126] \\
\hline $\mathrm{Ag} / \mathrm{Ag}_{2} \mathrm{O}$ & MO degradation & $\begin{array}{c}84 \%, 78 \% \text { and } 88 \% \text { of MO are degraded under UV, visible and NIR } \\
\text { irradiation }\end{array}$ & 2016 & [136] \\
\hline $\mathrm{CoP} / \mathrm{g}-\mathrm{C}_{3} \mathrm{~N}_{4}$ & $\mathrm{H}_{2}$ evolution & The 2D/2D structure performs 2.1 times better than $0 \mathrm{D} / 2 \mathrm{D}$ structure & 2018 & [137] \\
\hline $\mathrm{Ru} / \mathrm{TiO}_{2}$ & Aerobic oxidation of benzyl alcohol & $84 \%$ of MO degraded for $25 \mathrm{~min}$ & 2016 & {$[138]$} \\
\hline $\mathrm{Ag} / \mathrm{CeO}_{2}$ & MB degradation & $95.33 \%$ of MB degraded within 30 min & 2015 & [139] \\
\hline $\mathrm{Pd} / \mathrm{BiFeO}_{3}$ & MO degradation & 10.7 times higher than $\mathrm{BiFeO}_{3}$ & 2016 & [140] \\
\hline CQDs/H- $\gamma$-TaON & $\mathrm{H}_{2}$ evolution & $\mathrm{H}_{2}$ evolution rate of $496.5 \mu \mathrm{mol} \mathrm{h}^{-1}$ & 2015 & [141] \\
\hline $1 \mathrm{~T}-\mathrm{MoS}_{2} / \mathrm{CdS}$ & $\mathrm{H}_{2}$ evolution & 39 times higher than pure $\mathrm{CdS}$ & 2016 & [142] \\
\hline $\mathrm{CdS} / \mathrm{Cd}$ & $\mathrm{H}_{2}$ evolution & $\mathrm{H}_{2}$ evolution rate of $1.68 \mathrm{mmol} \mathrm{h}^{-1}$ & 2015 & {$[31]$} \\
\hline $1 \mathrm{~T}-\mathrm{MoS}_{2} / \mathrm{O}-\mathrm{g}-\mathrm{C}_{3} \mathrm{~N}_{4} 2 \mathrm{D}$ & $\mathrm{H}_{2}$ evolution & $\mathrm{H}_{2}$ evolution rate of $1841.72 \mu \mathrm{mol} \mathrm{h}^{-1} \mathrm{~g}^{-1}$ & 2018 & {$[143]$} \\
\hline $\mathrm{Ni} / \mathrm{NiTe}_{2}$ & $\mathrm{H}_{2}$ evolution & A rate of $2214.2 \mu \mathrm{mol} \mathrm{g}^{-1} \mathrm{~h}^{-1}$ & 2020 & [144] \\
\hline $\mathrm{Ag} / \mathrm{CN}$ & $\mathrm{H}_{2}$ evolution & $\mathrm{H}_{2}$ evolution rate of $364.6 \mu \mathrm{mol} \mathrm{g}-1$ & 2019 & {$[145]$} \\
\hline $\mathrm{Ag}_{2} \mathrm{WO}_{4} / \mathrm{Ti}_{3} \mathrm{C}_{2}$ & Degradation of TC and SFE & Degradation rate of $62.9 \%$ and $88.6 \%$, respectively & 2019 & [146] \\
\hline $\mathrm{Bi} / \mathrm{Bi}_{2} \mathrm{O}_{2} \mathrm{CO}_{3}$ & MB degradation & Complete degradation within $60 \mathrm{~min}$ & 2016 & [147] \\
\hline $\mathrm{Pt} / \mathrm{PbS}$ & $\mathrm{H}_{2}$ evolution & 14.38 times higher than $\mathrm{PbS}$ & 2017 & [148] \\
\hline
\end{tabular}



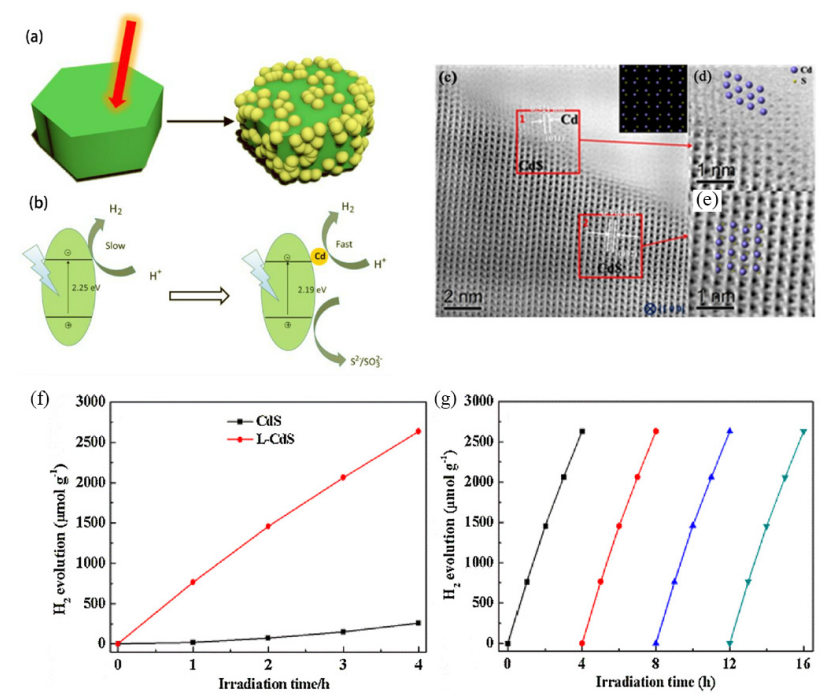

Fig. 14. (a) A schematic of the generation of CdS/Cd Schottky junction. (b) Mechanism of the improved photocatalytic activity for CdS/Cd. (c) STEM image of CdS/Cd viewed from the [100] direction. (d,e) Enlarged view of the corresponding areas in (c). (f) Comparison of the photocatalytic hydrogen evolution over $\mathrm{CdS}$ and $\mathrm{CdS} / \mathrm{Cd}$. (g) Cycling hydrogen evolution measurements for $\mathrm{CdS} / \mathrm{Cd}$. (reproduced with permission [135], copyright 2019, Elsevier).
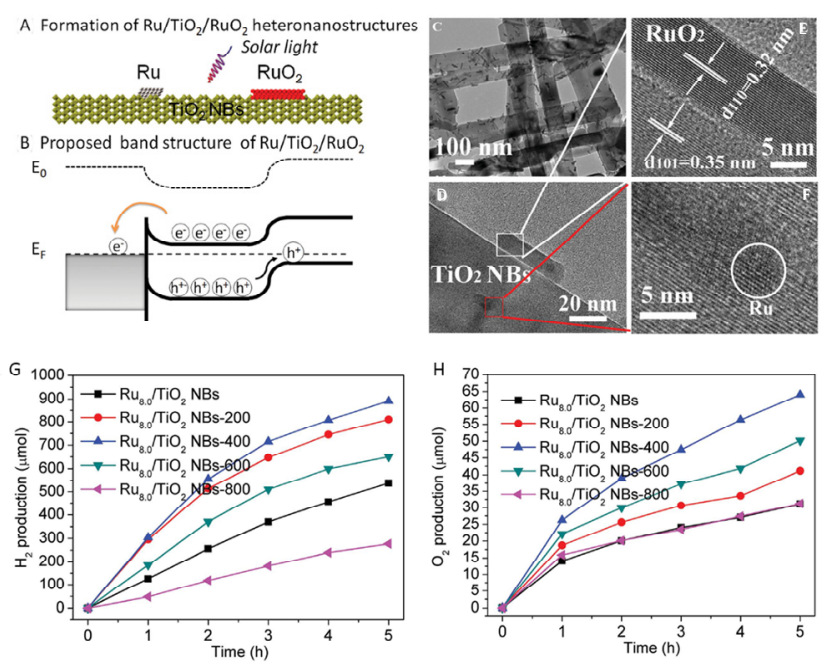

Fig. 15. (A) Illustration of the structure of $\mathrm{Ru} / \mathrm{TiO}_{2} / \mathrm{RuO}_{2}$ heterojunctions. (B) Band structure of the $\mathrm{Ru} / \mathrm{TiO}_{2} / \mathrm{RuO}_{2}$ heterojunctions. (C,D,E,F TEM and HRTEM images of the $\mathrm{Ru} / \mathrm{TiO}_{2} / \mathrm{RuO}_{2}$ heterojunctions. $(\mathrm{G}, \mathrm{H})$ Photocatalytic $\mathrm{H}_{2}$ and $\mathrm{O}_{2}$ evolution over $\mathrm{Ru}_{8.0} / \mathrm{TiO}_{2}$ NBs-T, where $\mathrm{T}$ indicates the annealing temperatures. (reproduced with permission [125], copyright 2016, Wiley).

range of the MOF, while the Schottky heterojunction greatly accelerated the charge separation. Furthermore, to distinguish the great significance of the spatial position of Pt nanoparticles, the Pt/MIL-125/Au and MIL-125/Au samples were also prepared as references (Fig. 16). Interestingly, due to the spatial separation of Pt nanoparticles and Au nanorods by MIL-125, the sample Pt@MIL-125/Au demonstrated much better separation efficiency and lower charge transfer resistance than Pt/MIL-125/Au, where Pt nanoparticles and Au nanorods were co-dispersed on the MIL-125 surface. As a result, the
Pt@MIL-125/Au performed far more efficiently for photocatalytic hydrogen production than $\mathrm{Pt} / \mathrm{MOF} / \mathrm{Au}$ and MOF/Au. Large amount of noble metals was adopted in this work. To reduce the expenditure, other plasmonic metals such as $\mathrm{Al}$ or $\mathrm{Cu}$ could be considered as substitutes.

\subsection{S-scheme heterojunctions}

To fully exploit the reduction/oxidation ability of the photogenerated electrons/holes, the S-scheme heterojunctions are proposed and prepared very recently based on previous studies of heterojunction photocatalysts [154-163]. Due to the band similarity, the recombination mechanism in S-scheme heterojunctions should be carefully verified to distinguish the S-scheme from the type II heterojunctions. Rational theoretical calculations combined with powerful characterization techniques could be a convinced way to confirm the S-scheme mechanism. Particularly, theoretical calculations such as density functional theory simulations help to determine the work functions of various semiconductors and charge distributions at the heterojunction interface, and thus the internal electric field at the interface. Further, in situ irradiated X-ray photoelectron spectroscopy (XPS) measurement could observe the electron flow direction at the heterojunction interface before and after light irradiation. In addition, electron paramagnetic resonance (EPR) spectrum could detect the redox radicals with specific reaction potentials, such as $\bullet \mathrm{OH}$ or $\bullet^{-\mathrm{O}_{2}}$, which helps to determine the oxidation and reduction sites located in different parts of the heterojunction. Finally, a S-scheme charge transfer pathway could be confirmed with photoinduced electrons and holes accumulated in the semiconductor of more negative CB and the semiconductor of more positive VB, respectively. Some S-scheme heterojunction photocatalysts are compared in Table 5.

For instance, Xia et al. [177] designed a 0D/2D S-scheme heterojunction of $\mathrm{CeO}_{2} / \mathrm{PCN}$ (polymeric carbon nitride) for the
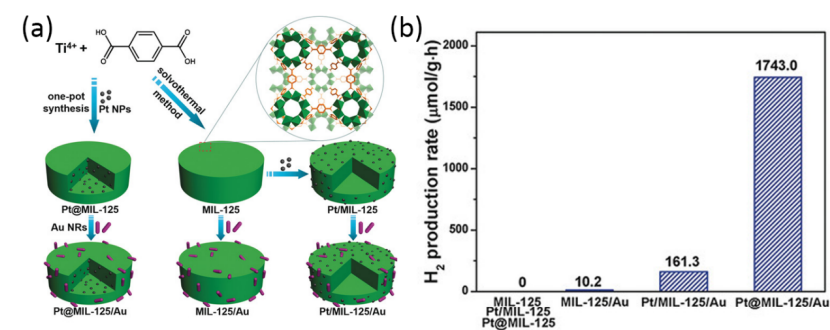

(c)

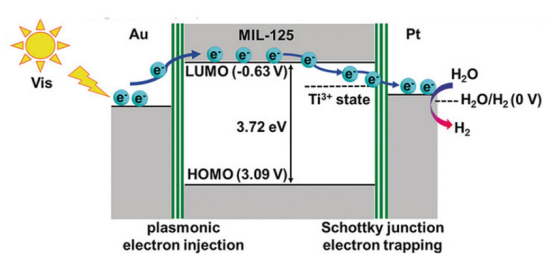

Fig. 16. (a) Schematic illustration showing the synthesis of Pt@MIL-125/Au and the corresponding Pt/MIL-125/Au and MIL-125/Au analogues. (b) Photocatalytic H2 production rates of different catalysts. (c) Schematic illustration showing the electron migration at the two metal/MOF interfaces. (reproduced with permission [153], copyright 2018, Wiley). 
Table 5

Comparison of some recently developed S-Scheme heterojunction photocatalysts.

\begin{tabular}{|c|c|c|c|c|}
\hline Heterojunction & Application & Performance & Year & Ref. \\
\hline $\mathrm{V}_{2} \mathrm{O}_{5} / \mathrm{g}-\mathrm{C}_{3} \mathrm{~N}_{4}$ & RhB degradation & 7.3 and 13.0 times higher than individual $\mathrm{g}-\mathrm{C}_{3} \mathrm{~N}_{4}$ and $\mathrm{V}_{2} \mathrm{O}_{5}$ & 2016 & [154] \\
\hline $\mathrm{Bi}_{2} \mathrm{Fe}_{4} \mathrm{O}_{9} / \mathrm{Bi}_{2} \mathrm{WO}_{6}$ & $\mathrm{RhB}$ degradation & Complete degradation within $90 \mathrm{~min}$ & 2018 & [155] \\
\hline $\mathrm{Ag}_{2} \mathrm{CrO}_{4} / \mathrm{GO}$ & MB degradation & 3.5 times higher than $\mathrm{Ag}_{2} \mathrm{CrO}_{4}$ & 2015 & [156] \\
\hline $\mathrm{TiO}_{2} / \mathrm{CdS}$ & $\mathrm{CO}_{2}$ reduction & 3.5 and 5.4 times higher than $\mathrm{CdS}$ and $\mathrm{TiO}_{2}$ & 2019 & [157] \\
\hline $\mathrm{BP} / \mathrm{Bi}_{2} \mathrm{WO}_{6}$ & $\mathrm{H}_{2}$ generation & 9.15 times that of pristine & 2019 & [158] \\
\hline $\mathrm{ZnO} / \mathrm{CeO}_{2}$ & $\mathrm{RhB}$ degradation & 2.5 and 1.7 times than pristine $\mathrm{ZnO}$ and $\mathrm{CeO}_{2}$ & 2018 & [159] \\
\hline $\mathrm{CdS} / \alpha-\mathrm{Fe}_{2} \mathrm{O}_{3}$ & $\mathrm{H}_{2}$ generation & $\mathrm{H}_{2}$ production rate of $45 \mathrm{mmol} \mathrm{h}^{-1} \mathrm{~g}^{-1}$ and high quantum efficiency of $46.9 \%$ & 2020 & [160] \\
\hline $\mathrm{CdS} / \mathrm{g}-\mathrm{C}_{3} \mathrm{~N}_{4}$ & $\mathrm{H}_{2}$ generation & $\mathrm{H}_{2}$ production rate of $15.3 \mathrm{mmol} \mathrm{g}^{-1} \mathrm{~h}^{-1}$ & 2020 & [161] \\
\hline $\mathrm{WO}_{3}\left(\mathrm{H}_{2} \mathrm{O}\right)_{0.333} / \mathrm{Ag}_{3} \mathrm{PO}_{4}$ & MB degradation & Complete degradation in 4 min & 2019 & [162] \\
\hline $\mathrm{g}-\mathrm{C}_{3} \mathrm{~N}_{4} / \mathrm{C}-\mathrm{TiO}_{2}$ & $\mathrm{RhB}$ degradation & 150 times higher than $\mathrm{TiO}_{2}$ & 2019 & [163] \\
\hline $\mathrm{WO}_{3} / \mathrm{g}-\mathrm{C}_{3} \mathrm{~N}_{4}$ & $\mathrm{H}_{2}$ generation & $\mathrm{H}_{2}$ production rate of $982 \mu \mathrm{mol} \mathrm{h}^{-1} \mathrm{~g}^{-1}$ & 2019 & [58] \\
\hline $\mathrm{g}-\mathrm{C}_{3} \mathrm{~N}_{4} / \mathrm{Ag}_{3} \mathrm{VO}_{4}$ & MB degradation & Degradation rate of $99.3 \%$ within $8 \mathrm{~min}$ & 2019 & [164] \\
\hline $\mathrm{SnFe}_{2} \mathrm{O}_{4} / \mathrm{ZnFe}_{2} \mathrm{O}_{4}$ & Tetracycline degradation & $93.2 \%$ removal efficiency & 2020 & [165] \\
\hline $\mathrm{Ni}_{2} \mathrm{P}-\mathrm{SNO} / \mathrm{CdS}-\mathrm{D}$ & Hydrogen production & Hydrogen production rate of $7808 \mu \mathrm{mol} \mathrm{g}^{-1} \mathrm{~h}^{-1}$ & 2020 & [166] \\
\hline $\mathrm{BiOBr} / \mathrm{Bi}_{2} \mathrm{MoO}_{6}$ & Degradation of RhB & $66.7 \%$ total organic carbon could be removed & 2017 & [167] \\
\hline $\mathrm{Bi}_{2} \mathrm{~S}_{3} / \mathrm{Pg}-\mathrm{C}_{3} \mathrm{~N}_{4}$ & MB degradation & 29.74 times greater than $\mathrm{Bi}_{2} \mathrm{~S}_{3}$ & 2019 & [168] \\
\hline g- $\mathrm{C}_{3} \mathrm{~N}_{4} / \mathrm{SnS}_{2}$ & $\mathrm{CO}_{2}$ reduction & $\mathrm{CH}_{3} \mathrm{OH}$ yield of $2.3 \mu \mathrm{mol} \mathrm{g}{ }^{-1}$ and $\mathrm{CH}_{4}$ yield of $0.64 \mu \mathrm{mol} \mathrm{g}^{-1}$ & 2017 & [169] \\
\hline $\mathrm{WO}_{3} / \mathrm{g}-\mathrm{C}_{3} \mathrm{~N}_{4}$ & TC degradation & Degradation rate of $90.54 \%$ within 120 min & 2020 & [170] \\
\hline $\mathrm{Pg}-\mathrm{C}_{3} \mathrm{~N}_{4} / \mathrm{Zn}_{0.2} \mathrm{Cd}_{0.8} \mathrm{~S}$ & $\mathrm{H}_{2}$ generation & hydrogen production rate of $6.69 \mathrm{mmol} \mathrm{g}^{-1} \mathrm{~h}^{-1}$ & 2020 & [171] \\
\hline $\mathrm{Ag}_{3} \mathrm{VO}_{4} / \mathrm{BiVO}_{4}$ & $\begin{array}{l}\text { Photocatalytic reduction of } \mathrm{Cr}^{6+} \\
\text { and oxidation of Bisphenol S }\end{array}$ & Photocatalytic reduction and oxidation efficiency of $74.9 \%$ and $94.8 \%$ & 2019 & [172] \\
\hline $\mathrm{LaCoO}_{3} / \mathrm{g}-\mathrm{C}_{3} \mathrm{~N}_{4}$ & Phenol degradation & 7.5 times higher than $\mathrm{g}-\mathrm{C}_{3} \mathrm{~N}_{4}$ & 2019 & [173] \\
\hline $\mathrm{Cd}_{0.5} \mathrm{Zn}_{0.5} \mathrm{~S} / \mathrm{g}-\mathrm{C}_{3} \mathrm{~N}_{4}$ & Dye degradation & 13 times higher than $\mathrm{g}-\mathrm{C}_{3} \mathrm{~N}_{4}$ & 2020 & [174] \\
\hline $\mathrm{NiO} / \mathrm{BiOI}$ & $\mathrm{RhB}$ degradation & 8 times higher than $\mathrm{NiO}$ & 2020 & [175] \\
\hline $\mathrm{Bi}_{2} \mathrm{~S}_{3} / \mathrm{BiFeO}_{3}$ & TC degradation & 6 times higher than $\mathrm{Bi}_{2} \mathrm{~S}_{3}$ & 2020 & [176] \\
\hline
\end{tabular}

sterilization towards Staphylococcus Aureus. Utilizing the wet chemistry method with following heat treatment, $\mathrm{CeO}_{2}$ quantum dots were decorated on the PCN nanosheets uniformly without any usage of complicated organic solvent (Fig. 17). The 0D/2D configuration reduces effectively the diffusion length of photogenerated charges, while the large surface area of PCN nanosheets provide abundant sites to immobilize $\mathrm{CeO}_{2}$ quan- tum dots. Furthermore, due to the formation of S-scheme heterojunction, the $\mathrm{CeO}_{2} / \mathrm{PCN}$ composite not only exhibited much higher charge separation efficiency than $\mathrm{CeO}_{2}$ or PCN, but also preserved full redox ability. As a result, this novel material shows high photocatalytic anti-bacteria efficiency, with a sterilization rate of $88.1 \%$, which is 2.7 and 8.2 times that of pure $\mathrm{CeO}_{2}(32.2 \%)$ and PCN (10.7\%), respectively.
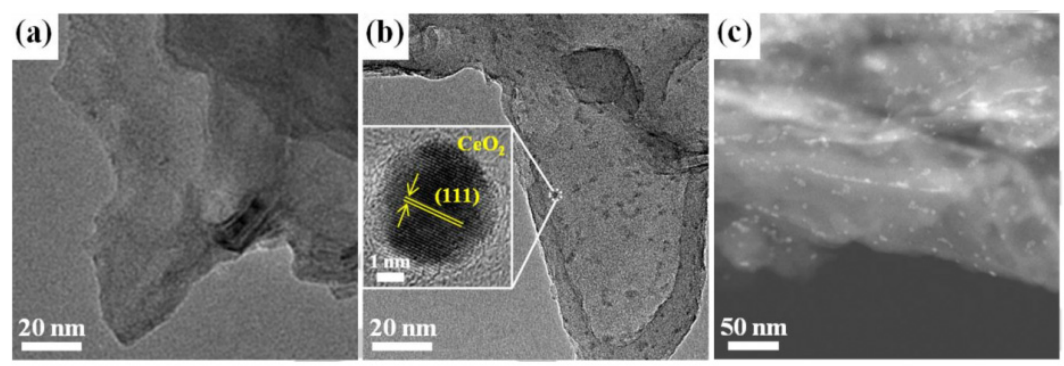

(d)

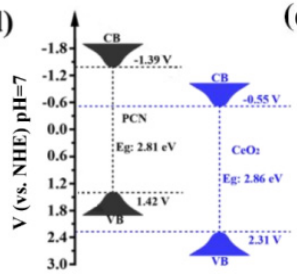

(e)

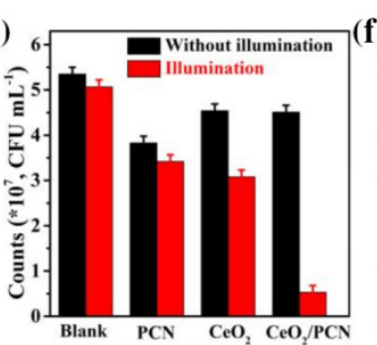

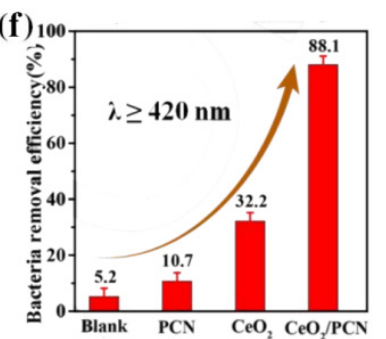

Fig. 17. (a) TEM image of PCN nanosheets. (b) TEM image of the $\mathrm{Ce}_{2} / \mathrm{PCN}$ heterojunction photocatalyst. Inset: corresponding HRTEM image of (111) plane of $\mathrm{CeO}_{2}$. (c) HAADF-TEM image of the $\mathrm{CeO}_{2} / \mathrm{PCN}$ heterojunction photocatalyst. (d) Band structure of pure $\mathrm{CeO}_{2}$ and $\mathrm{PCN}$. (e) The statistic counts of bacteria colonies treated with different samples, respectively. (f) The bacteria removal efficiency over the prepared samples. (reproduced with permission [177], copyright 2020, Wiley). 
One-dimensional nanostructure is also a promising morphology for high-efficient photocatalysis. Ge et al. [178] fabricated S-scheme $\mathrm{TiO}_{2} / \mathrm{CdS}$ composite nanofibers to facilitate the photocatalytic $\mathrm{H}_{2}$ production. The well-distributed $\mathrm{TiO}_{2} / \mathrm{CdS}$ nanofibers were prepared through a one-pot in situ method, where electrospinning and following low-temperature solid-phase synthesis were included. The $\mathrm{TiO}_{2} / \mathrm{CdS}$ composites showed excellent photocatalytic $\mathrm{H}_{2}$ production activities compared to pure $\mathrm{TiO}_{2}$ and CdS (Fig. 18). Concretely, the sample TC10 exhibited the best activity with an apparent quantum efficiency of $10.14 \%$, which outperforms most of its counterparts. This outstanding performance can be attributed to the formation of S-scheme heterojunction, which drives the photogenerated electrons to transfer toward CdS to consume the photogenerated holes in $\mathrm{TiO}_{2}$, leaving net electrons with higher reduction potential. The $\mathrm{S}$-scheme recombination mechanism is verified by the EPR spectrum of TC10, where the signal of $\bullet \mathrm{OH}$ radicals are observed. Otherwise, the holes in the $\mathrm{VB}$ of $\mathrm{TiO}_{2}$ will migrate to that of $\mathrm{CdS}$, the energy level of which is not enough to produce $\bullet \mathrm{OH}$, eliminating its EPR signal.

Black phosphorus (BP) has been regarded as an emerging material for photocatalysis. Li et al. [179] coupled exfoliated BP with $\mathrm{BiOBr}$ nanosheets to construct a novel layered $\mathrm{BP} / \mathrm{BiOBr}$ heterojunction photocatalyst for tetracycline (TC) removal and oxygen evolution. Through a facile solvothermal method, $\mathrm{BiOBr}$ nanosheets were self-assembled on the BP surface with intimate interfacial contact (Fig. 19). This S-scheme heterojunction created favorable conditions for the rapid separation and
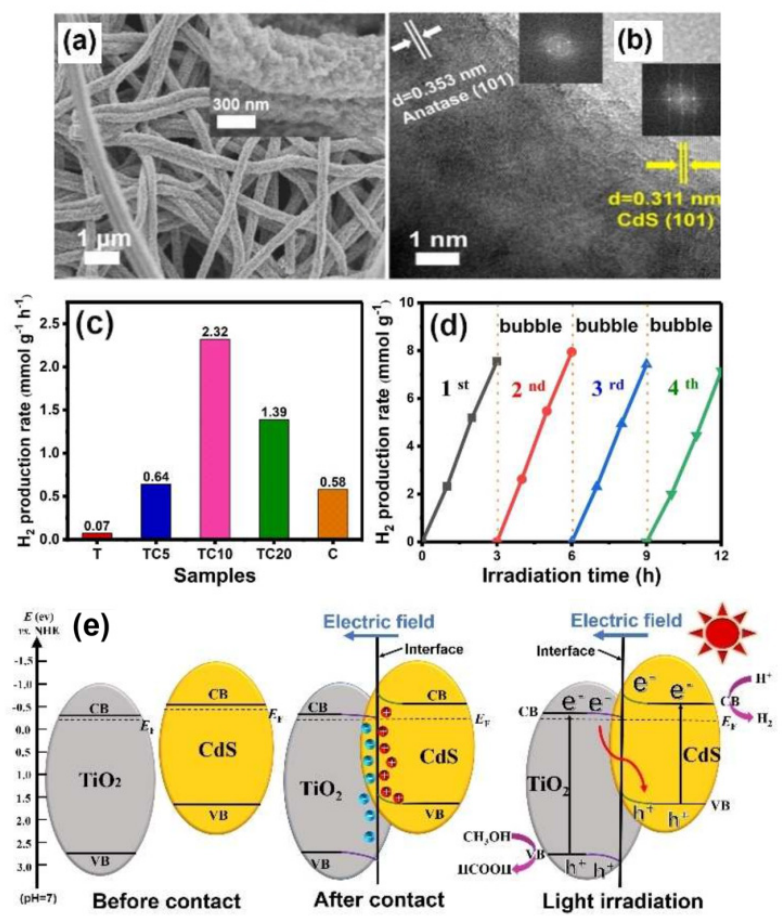

Fig. 18. (a,b) TEM and HRTEM images of the $\mathrm{TiO}_{2} / \mathrm{CdS}$ nanofiber. (c) Comparison of photocatalytic $\mathrm{H}_{2}$-production activity of T, TC5, TC10, TC20, and $\mathrm{C}$ samples. TCx: $\mathrm{T}$ and $\mathrm{C}$ represent $\mathrm{TiO}_{2}$ and $\mathrm{CdS}$, respectively, $x$ indicates the weight percentage of $\mathrm{CdS}$ with respect to $\mathrm{TiO}_{2}$. (d) $\mathrm{Cy}$ cling $\mathrm{H}_{2}$-production stability for the TC10 sample. (e) S-scheme charge separation and pathway in $\mathrm{TiO}_{2} / \mathrm{CdS}$ nanofiber. (reproduced with permission [178], copyright 2019, Wiley). transfer of photogenerated electron-hole pairs and retained the useful electrons and holes with higher redox potential. As a result, the unique $\mathrm{BP} / \mathrm{BiOBr}$ sample yields superior photocatalytic performance, including an apparent reaction rate constant of $0.021 \mathrm{~min}^{-1}$ for TC degradation and a $\mathrm{O}_{2}$ evolution rate of $89.5 \mu \mathrm{mol} \mathrm{g}-1 \mathrm{~h}^{-1}$, which is 7.8 and 7.0 times than that of pure $\mathrm{BiOBr}$, respectively. The oxygen evolution reaction potential is more positive than the $\mathrm{VB}$ position of $\mathrm{BP}$, which indicates the oxygen evolution can only take place at the $\mathrm{VB}$ of $\mathrm{BiOBr}$ through the S-scheme charge transfer pathway. It is noted that the BP in this work presents a morphology of nanosheets. A quantum dot morphology may further improve the photocatalytic activity in consideration of larger contact area and more active sites.

Crystalline covalent organic frameworks (COFs), possessing large surface areas and tunable structures, offering abundant active sites, are expected to be promising building blocks for constructing highly efficient photocatalysts. Most recently, Zhang et al. [180] proposed a strategy to create organic/inorganic S-scheme photocatalysts for $\mathrm{CO}_{2}$ reduction with $\mathrm{H}_{2} \mathrm{O}$ as the electron donor. A systemic organic/inorganic COF/SCs (semiconductor) were prepared by condensation of COF precursors and hydroxyl-containing $\mathrm{SCs}\left(\mathrm{TiO}_{2}, \mathrm{Bi}_{2} \mathrm{WO}_{6}\right.$, and $\alpha-\mathrm{Fe}_{2} \mathrm{O}_{3}$ ), as illustrated in Fig. 20(a), forming S-Scheme heterojunctions with COFs as the reduction catalyst and SCs as the oxidation catalyst, connected by covalent bonds. The COF/SCs samples exhibit outstanding photocatalytic activities. As shown in Figs. 20(b) and (c), COF-318/ $\mathrm{TiO}_{2}$ displays an op-
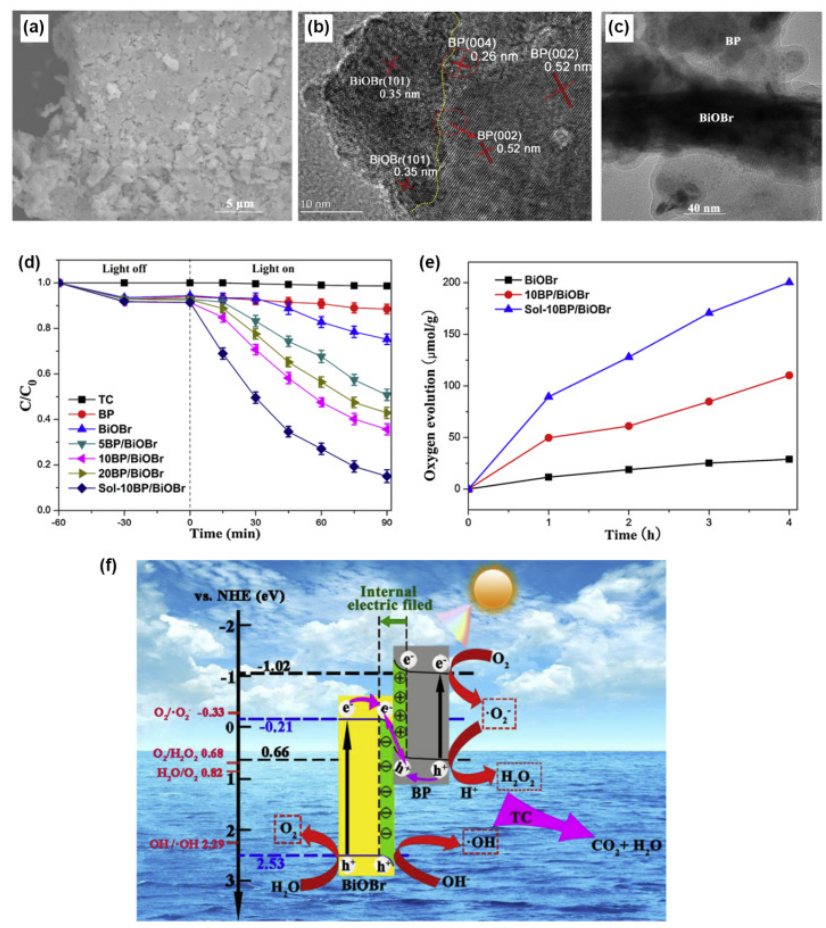

Fig. 19. $(a, b, c)$ SEM, TEM and HRTEM images of $\mathrm{BP} / \mathrm{BiOBr}$ photocatalyst. (d) Photocatalytic degradation efficiency of tetracycline (TC) over various samples. (e) Photocatalytic oxygen evolution rate of various samples. (f) Schematic illustration for the charge transfer and reaction mechanism. BP: Black phosphorus. $x \mathrm{BP} / \mathrm{BiOBr}: x$ indicates the weight ratio of $\mathrm{BP}$ respect to $\mathrm{BiOBr}$. (reproduced with permission [179], copyright 2020, Elsevier). 

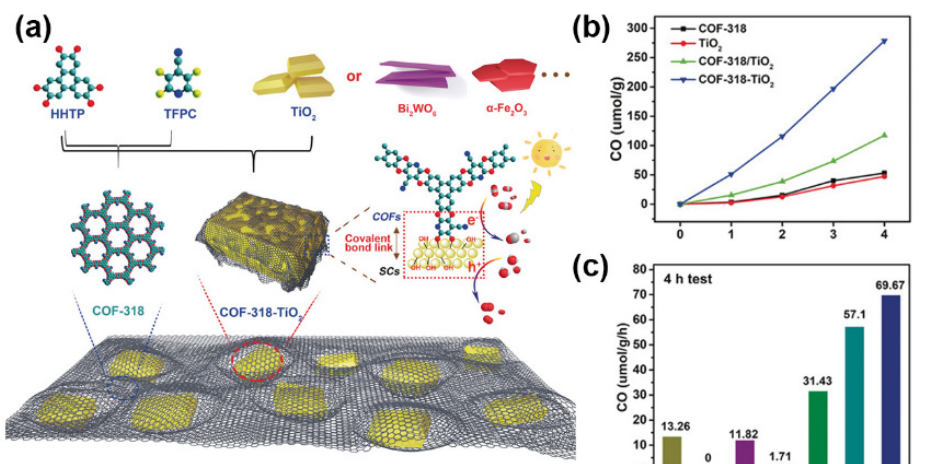

(c)

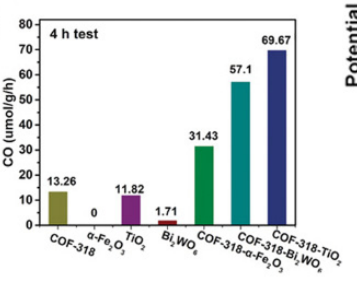

(d)

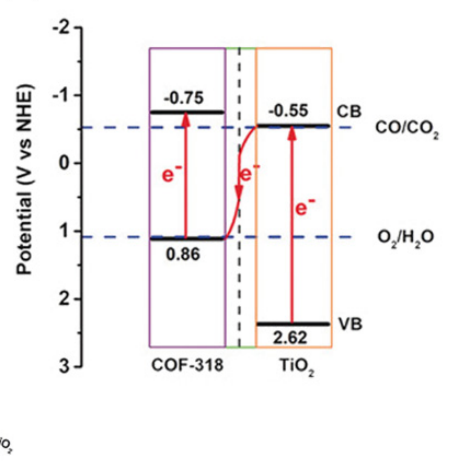

Fig. 20. (a) Schematic illustration of the preparation of COF/SC photocatalysts. (b,c) Photocatalytic performance of the prepared COF/SC samples. (d) Schematic charge separation in $\mathrm{COF} / \mathrm{SC}$ with $\mathrm{COF}-138 / \mathrm{TiO}_{2}$ as an example. (reproduced with permission [180], copyright 2020, Wiley).

timal CO formation rate of $278.7 \mu \mathrm{mol} \mathrm{g}-1$, which is one of the highest values among $\mathrm{CO}_{2}$ reduction photocatalysts, much better than pristine $\mathrm{COF}-318$ and $\mathrm{TiO}_{2}$. The enhanced performance is attributed to the efficient electron transfer from $\mathrm{TiO}_{2}$ to COF-318 and the formation of S-Scheme heterojunction, which is reflected by the comparison of electrochemical potentials shown in Fig. 20(d), where the $\mathrm{CB}$ position of $\mathrm{TiO}_{2}$ and the $\mathrm{VB}$ position of COF-138 exhibit very close levels with reference to the corresponding redox potentials of $\mathrm{CO} / \mathrm{CO}_{2}$ and $\mathrm{O}_{2} / \mathrm{H}_{2} \mathrm{O}$ reactions, respectively.

\subsection{Surface heterojunctions}

The atom arrangement and density could be different between different facets of a crystal. As a result, the electron movement and band structure on different facets may be diverse, which enables the possibility to design a heterojunction on a single semiconductor, namely the surface heterojunction. $\mathrm{TiO}_{2}$ and $\mathrm{BiVO}_{4}$ are the most-studied materials to construct a surface heterojunction [181-192]. For example, Liu et al. [188] prepared various $\mathrm{TiO}_{2}$ surface heterojunctions with different (101)/(001) ratios by controlling the morphology of the $\mathrm{TiO}_{2}$ crystal. Truncated octahedral bipyramid $\mathrm{TiO}_{2}$ nanocrystals were synthesized in a solution system consisting of titanium butoxide, water, and hydrofluoric acid (HF). Interestingly, the morphology and thus the facet exposure percentage could be precisely controlled by adjusting the $\mathrm{HF} / \mathrm{H}_{2} \mathrm{O}$ ratio. The relative band position of (001) facets and (101) facets was shown in Fig. 21, matching a type II band alignment. Thus, the electrons transfer from (001) to (101) facets and holes transfer the other way around were facilitated due to the formation of the surface heterojunction. Moreover, the ratio of (101) to (001) were optimized to maximize the production of reactive oxygen species and the antibacterial activity. Experimental results revealed that the $\mathrm{TiO}_{2}$ crystal with a ratio of 1.78 exhibited the best antibacterial performance, which was ascribed to the optimal activation of oxidative stress.

Rutile $\mathrm{TiO}_{2}$ has not achieved photocatalytic activity comparable to that of anatase $\mathrm{TiO}_{2}$ due to its higher recombination rate of electron-hole pairs. To obtain better photocatalytic activity of rutile $\mathrm{TiO}_{2}$, Gao et al. [190] designed surface hetero- junctions. As shown in Fig. 22, the fabrication of $\mathrm{FH}_{-} \mathrm{TiO}_{2}$ (facet heterojunction) was achieved with a two-step hydrothermal method. First, rutile $\mathrm{TiO}_{2}$ nanorods were grown on FTO substrate through the first hydrothermal step. Then, $\mathrm{TiO}_{2}$ nanosheets were assembled on the $\mathrm{TiO}_{2}$ nanorods through the second hydrothermal step, with special consideration on the reaction time, initial titanium precursor concentration, and temperature. TEM and XRD analysis reveals that the exposed dominant facet of the top portion of $\mathrm{TiO}_{2}$ is the (101) facet, and the body portion is the (110) facet, forming countless (101)/(110) surface heterojunctions. The photocatalytic hydrogen evolution performance of the samples is displayed in Fig. 22(g), from which it can be seen the hydrogen evolution

(a)

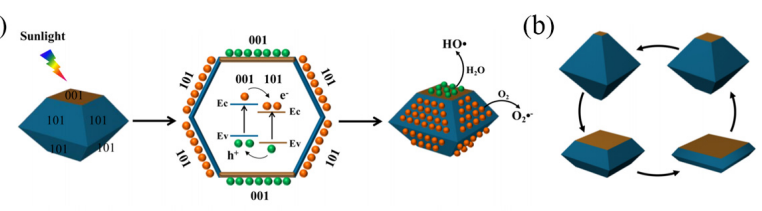

(c)

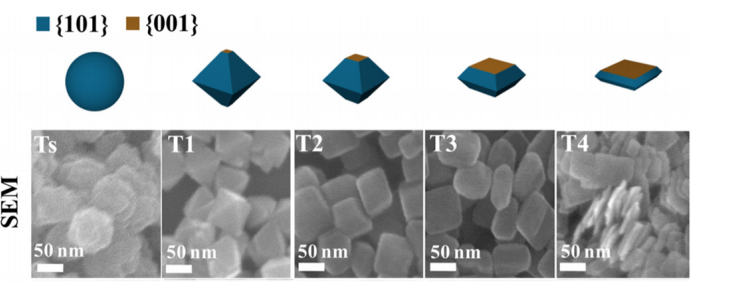

(d)

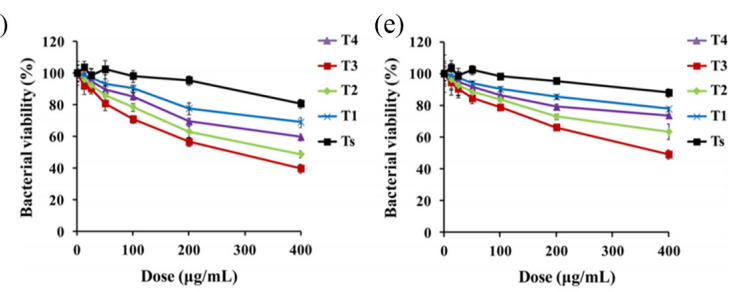

Fig. 21. (a) Schematic illustration of the (101)/(001) surface heterojunction of $\mathrm{TiO}_{2}$. (b) Schematic illustration of the adjustment of the facet ratio through morphology control. (c) SEM images of samples with different facet ratios. The $(101) /(001)$ facet ratios of T1, T2, T3, and T4 were $49,11.5,1.78$, and 0.087 , respectively. (d,e) Bacterial viability of $E$. coli and $\mathrm{S}$. aureus exposed to different concentrations of $\mathrm{TiO}_{2}$ nanocrystals, respectively. (reproduced with permission [188], copyright 2017, American Chemical Society). 
(a)

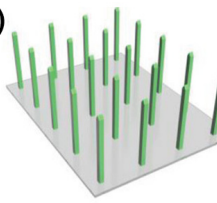

(b)
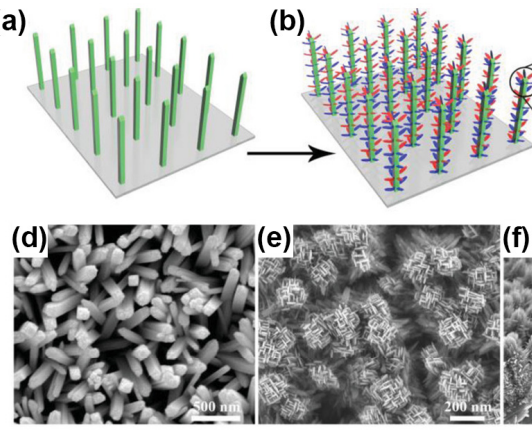

(g)

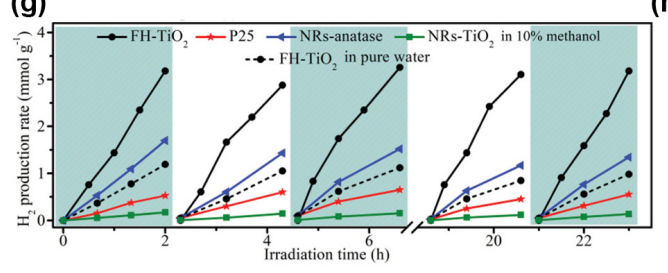

(c)

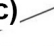

4
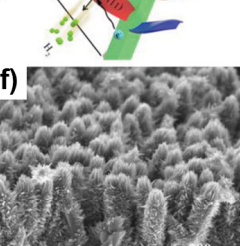

(h)

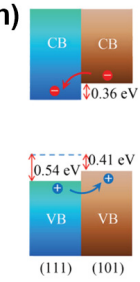

Fig. 22. $(a, b)$ Schematic illustration of the formation of $\mathrm{TiO}_{2}$ surface heterojunction. (c) Enlarged view showing the exposed facets of $\mathrm{TiO}_{2}$. (d-f) SEM images of $\mathrm{TiO}_{2}$ nanorods and $\mathrm{TiO}_{2}$ nanorods loaded with nanosheets. (g) Photocatalytic performance of various samples. (h) Band alignment of the (111) and (101) facets of rutile $\mathrm{TiO}_{2}$. $\mathrm{FH}-\mathrm{TiO}_{2}$ : Facet Heterojunction $\mathrm{TiO}_{2}, \mathrm{TiO}_{2}$ nanorods loaded with nanosheets; P25: commercial $\mathrm{TiO}_{2}$; NRs-anatase: nanorods with anatase phase; $\mathrm{NRs} \mathrm{TiO}_{2}$ : nanorods with rutile phase. (reproduced with permission [190], copyright 2019, Wiley).

rate of $\mathrm{FH}-\mathrm{TiO}_{2}$ is 45 times higher than pure rutile $\mathrm{TiO}_{2}$. The underlying physics of enhanced performance can be understood as boosted charge separation due to the formation of surface heterojunctions, which drives the photogenerated electron transferring from (101) facets to (111) facets, the photogenerated holes from (111) facets to (101) facets.

Surface heterojunctions based on Bi-based semiconductors like $\mathrm{BiVO}_{4}$ or BiOI were also constructed [196,197,204,205]. For instance, He et al. [205] reported surface heterojunctions based on BiOI, with enhanced photocatalytic activity for phenol degradation. Hierarchically structured BiOI were fabricated through a facile method including solid-state reaction and subsequent hydrolysis at room temperature (Fig. 23). To optimize the photocatalytic activity, the ratio of (110) to (001) facets was tuned by controlling the volume of water added in the hydrolysis. The different water volume created different $\mathrm{pH}$ environments, which played a key role in regulating the growth direction of BiOI nanoplates. Samples with various facet ratios were prepared and measured. BiOI-80 exhibited the best degradation performance, which was attributed to two factors. On one hand, the hierarchical structure of BiOI-80 enables strongest light absorption and offers the highest specific surface. On the other hand, the most surface heterojunctions are formed, which improves the separation of electrons and holes.

In short, some typical surface heterojunction photocatalysts are compared in Table 6.

\subsection{Graphene-based heterojunctions}

Tremendous heterojunction photocatalysts based on gra- phene nanosheets have been developed due to their excellent electric conductivity, efficient charge separation ability and high surface areas [206,207]. Moreover, the diversity of graphene offers inexhaustible opportunities for the construction of heterojunction based photocatalysts. For example, the graphene exhibits amazing structural diversity, like 0D graphene quantum dots, 1D graphene nanoribbons, 2D graphene nanosheets and 3D graphene networks. The band structure and further the electrical or optical properties of graphene also show high tunability through the change of many factors like the number of layers, edge structure and the defect density [208], which enables graphene to form various types of heterojunctions with appropriate materials, such as type II heterojunction, S-scheme heterojunction, or Schottky heterojunction [209-223], as listed in Table 7.

Xia et al. [236] reported the combination of highly crystalline carbon nitride (CN) nanorods and graphene to form an ordered 2D/1D heterojunction (Fig. 24). The hybrid material exhibited excellent photocatalytic performance for the $\mathrm{CO}_{2}$ reduction in the gas phase, in the absence of any cocatalyst or sacrificial agent. The loading amount of graphene was optimized to achieve best $\mathrm{CO}_{2}$ conversion rate. Experimental results revealed that the best performance of graphene supported 1D nano-arrays of crystalline CNs could be $12.63 \mu \mathrm{mol} \mathrm{h}^{-1}$ $\mathrm{g}^{-1}$, which is 6 times and 4 times that of bulk CN and pure crystalline $\mathrm{CN}$ nanorods, respectively. The formation of unique 2D/1D heterojunction of graphene/CNs accounts for the enhanced photocatalytic performance, which improves light har-

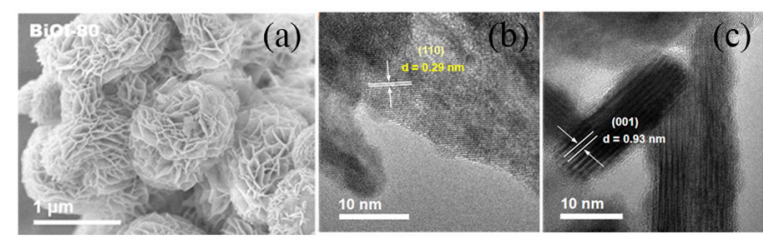

(d)

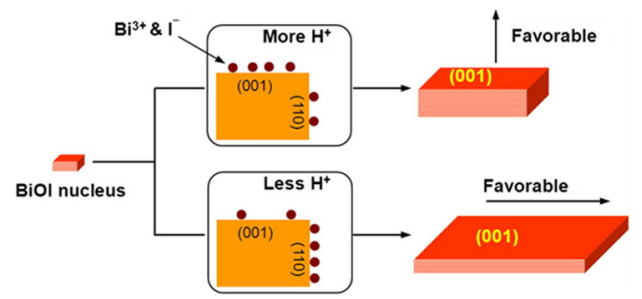

(e)
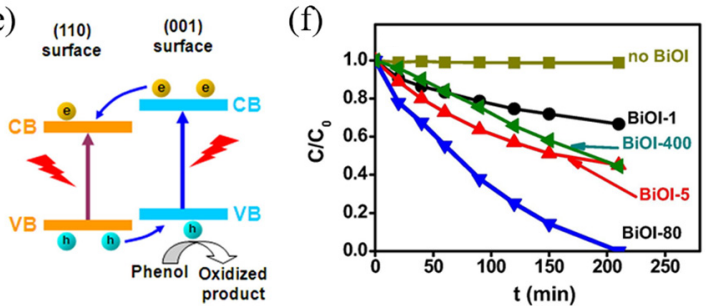

Fig. 23. (a) SEM image of BiOI. (b,c) HRTEM images of BiOI viewed from the perpendicular and parallel directions of the BiOI plate, respectively. (d) Schematic illustration of the growth of BiOI nanoplate at different PH values. (e) Band alignment of (110) and (001) facet of BiOI. (f) Degradation curves of phenol on BiOI samples. BiOI- $X: X$ means $X$ mL distilled water was added in the hydrolysis process. (reproduced with permission [205], copyright 2016, Elsevier). 
Table 6

Comparison of some recently developed surface heterojunction photocatalysts.

\begin{tabular}{|c|c|c|c|c|}
\hline Heterojunction & Application & Performance & Year & Ref. \\
\hline $\mathrm{TiO}_{2}(001) /(101)$ & $\mathrm{H}_{2}$ production & $\mathrm{H}_{2}$ evolution rate of $264 \mu \mathrm{mol} \mathrm{h}^{-1}$ & 2016 & [184] \\
\hline $\mathrm{TiO}_{2}(001) /(101)$ & Reduction $\mathrm{CO}_{2}$ to $\mathrm{CH}_{4}$ & $\mathrm{CH}_{4}$ production rate of $1.58 \mu \mathrm{mol} \mathrm{h}^{-1} \mathrm{~g}^{-1}$ & 2016 & [186] \\
\hline $\mathrm{TiO}_{2}(001) /(101)$ & Removing $\mathrm{Hg}^{0}$ & $87 \% \mathrm{Hg}^{0}$ removal efficiency & 2017 & {$[187]$} \\
\hline $\mathrm{TiO}_{2}(001) /(101)$ & Anti-bacteria & $50 \%$ decrease in the bacterial viability in $6 \mathrm{~h}$ & 2017 & [188] \\
\hline Rutile $\mathrm{TiO}_{2}(111) /(101)$ & $\mathrm{H}_{2}$ production & $0.566 \mathrm{mmol} \mathrm{g}^{-1} \mathrm{~h}^{-1} \mathrm{H}_{2}$ production rate in pure water & 2019 & {$[190]$} \\
\hline 18-facet $\mathrm{SrTiO}_{3}(001) /(110)$ & Water splitting & Fivefold enhancement of $\mathrm{AQE}$ than 6-facet $\mathrm{SrTiO}_{3}$ & 2016 & {$[193]$} \\
\hline $\mathrm{ZnGa}_{2} \mathrm{O}_{4}(110) /(111)$ & $\mathrm{H}_{2}$ production & $12.5 \mathrm{mmol} \mathrm{g}^{-1} \mathrm{~h}^{-1} \mathrm{H}_{2}$ production rate & 2017 & {$[194]$} \\
\hline $\mathrm{CaCu}_{3} \mathrm{Ti}_{4} \mathrm{O}_{12}(001) /(111)$ & TC degradation & 70 times higher than defect free $\mathrm{CaCu}_{3} \mathrm{Ti}_{4} \mathrm{O}_{12}$ & 2019 & [195] \\
\hline $\mathrm{m}^{-\mathrm{BiVO}_{4}(010) /(110)}$ & $\mathrm{O}_{2}$ evolution & Higher than plate-like $\mathrm{BiVO}_{4}$ & 2016 & [196] \\
\hline $\mathrm{BiOI}(001) /(110)$ & MO degradation & 71.4\% MO degradation efficiency & 2018 & [197] \\
\hline anatase $\mathrm{TiO}_{2}(001) /(101) / \mathrm{SnS}_{2}$ & MB degradation & 1.5 times better than pure $\mathrm{TiO}_{2}$ & 2017 & [198] \\
\hline anatase $\mathrm{TiO}_{2}(001) /(101) / \mathrm{ZnS}$ & MB degradation & 2 times better than pure $\mathrm{TiO}_{2}$ & 2017 & [199] \\
\hline $\mathrm{BiVO}_{4}(010) /(110)$ & RhB degradation & $53.8 \%$ degradation efficiency within $180 \mathrm{~min}$ & 2018 & [200] \\
\hline $\mathrm{In}_{2} \mathrm{O}_{3}$ loaded $\mathrm{BiVO}_{4}(010) /(110)$ & RhB degradation & 91\% degradation efficiency within $180 \mathrm{~min}$ & 2017 & [201] \\
\hline anatase $\mathrm{TiO}_{2}(001) /(101)$ & $\mathrm{H}_{2}$ production & a generation rate of $670 \mu \mathrm{mol} \mathrm{h}^{-1} \mathrm{~g}^{-1}$ & 2016 & [202] \\
\hline CdS loaded $\mathrm{TiO}_{2}(001) /(101)$ & 4-CP degradation & $96.12 \%$ degradation efficiency & 2018 & [203] \\
\hline anatase $\mathrm{TiO}_{2}(001) /(101)$ & $\mathrm{CO}_{2}$ Reduction & 21 times increasement & 2014 & [181] \\
\hline
\end{tabular}

vesting, $\mathrm{CO}_{2}$ capture, and interface charge transfer.

Recently, Bie et al. prepared a N-doped graphene (NG) and CdS composite, the NG/CdS hollow spheres (HS) for photocatalytic $\mathrm{CO}_{2}$ reduction [237]. The fabrication process and structure evolution of NG/CdS HS were displayed in Fig. 25(a)-(e). Using $\mathrm{SiO}_{2}$ spheres as templates, $\mathrm{CdS}$ shell was first grown on the surface. Then, various amount of pyridine was added to grow NG after pyrolysis in a tube furnace. Finally, the $\mathrm{SiO}_{2}$ spheres were removed after alkali etching, forming the hollow structure. The samples exhibit excellent $\mathrm{CO}_{2}$ reduction activity, as shown in Fig. 25(f). Specifically, the sample CdG2 outperforms its counterparts, with a $\mathrm{CO}$ and $\mathrm{CH}_{4}$ production rate of 2.59 and $0.33 \mu \mathrm{mol} \mathrm{g}^{-1} \mathrm{~h}^{-1}$, respectively, which are about four and five times higher than those of pure CdS. The NG contributes to the enhanced photocatalytic activity from two main aspects. On one hand, Schottky heterojunction is generated at the interface of NG/CdS (Fig. 25(g)), which prohibits the photogenerated electrons from drifting back to $\mathrm{CdS}$, facilitating the charge separation. On the other hand, $\mathrm{NG}$ acts as the $\mathrm{CO}_{2}$ adsorbent and activator that effectively promote the photocatalytic activity.

Besides forming heterojunctions with other materials, gra-

Table 7

Comparison of some recently developed graphene-based heterojunction photocatalysts.

\begin{tabular}{|c|c|c|c|c|c|}
\hline Heterojunction & Type & Application & Performance & Year & Ref. \\
\hline $\mathrm{BiVO}_{4} / \mathrm{G} / \mathrm{ZnSe}$ & Z-Scheme & Water splitting & 9 times higher than $\mathrm{ZnSe}$ & 2019 & [209] \\
\hline $\mathrm{CsPbBr}_{3} / \mathrm{GO}$ & Schottky & $\mathrm{CO}_{2}$ reduction & A rate of $23.7 \mu \mathrm{mol} / \mathrm{g}$ h with a selectivity over $99.3 \%$ & 2017 & {$[210]$} \\
\hline $\mathrm{BiFeO}_{3} / \mathrm{rGO}$ & Schottky & MB degradation & Complete degradation within $100 \mathrm{~min}$ & 2018 & [211] \\
\hline $\mathrm{Ag}_{2} \mathrm{CrO}_{4} / \mathrm{g}-\mathrm{C}_{3} \mathrm{~N}_{4} / \mathrm{GO}$ & S-Scheme & $\mathrm{CO}_{2}$ reduction & 1.5 times higher than $\mathrm{Ag}_{2} \mathrm{CrO}_{4} / \mathrm{g}-\mathrm{C}_{3} \mathrm{~N}_{4}$ & 2018 & [213] \\
\hline $\mathrm{TiO}_{2} / \mathrm{rGO}$ & Schottky & RhB degradation & A rate of $53.27 \%$ within $300 \mathrm{~min}$ & 2017 & {$[217]$} \\
\hline $\mathrm{rGO} / \mathrm{ZnO}$ & Schottky & RhB degradation & A rate of $99.6 \%$ within $180 \mathrm{~min}$ & 2017 & {$[218]$} \\
\hline $\mathrm{GO} \mathrm{QD} / \mathrm{TiO}_{2}$ & Type II & $\mathrm{H}_{2}$ evolution & $100 \mu \mathrm{mol} \mathrm{h}^{-1}$ & 2017 & {$[219]$} \\
\hline$(\mathrm{BiO})_{2} \mathrm{CO}_{3} / \mathrm{BiO}_{2-\mathrm{x}} /$ graphene & Z-Scheme & Removal of NO & 2 times higher than $(\mathrm{BiO})_{2} \mathrm{CO}_{3}$ & 2019 & {$[220]$} \\
\hline $\mathrm{ZnIn}_{2} \mathrm{~S}_{4} / \mathrm{G}$ & Schottky & $\mathrm{H}_{2}$ evolution & A rate of $40.85 \mu \mathrm{mol} \mathrm{g}^{-1} \mathrm{~h}^{-1}$ & 2020 & [221] \\
\hline TiO2/rGO-EDA & Schottky & $\mathrm{H}_{2}$ evolution & A rate of $224.9 \mu \mathrm{mol} \mathrm{g}^{-1} \mathrm{~h}^{-1}$ & 2020 & [222] \\
\hline $\mathrm{MoS}_{2} / \mathrm{N}$-doped G & S-Scheme & Degradation of $\mathrm{NH}_{3}$ & A degradation efficiency of $99.5 \%$ in $8 \mathrm{~h}$ & 2020 & [223] \\
\hline $\mathrm{N}-\mathrm{TiO}_{2} / \mathrm{N}$-doped $\mathrm{G}$ & Туре II & MB degradation & A degradation efficiency of $87.9 \%$ within $180 \mathrm{~min}$ & 2016 & {$[224]$} \\
\hline $\mathrm{Cu}_{2} \mathrm{O} / \mathrm{G} / \mathrm{TNA}$ & Type II & $\mathrm{CO}_{2}$ conversion & Methanol yield of $45 \mu \mathrm{mol} \mathrm{cm} \mathrm{ch}^{-2} \mathrm{~h}^{-1}$ & 2016 & {$[225]$} \\
\hline $\mathrm{P} 25 / \mathrm{Ag}_{3} \mathrm{PO}_{4} / \mathrm{GO}$ & Schottky & RhB degradation & 75\% degradation efficiency within $1 \mathrm{~h}$ & 2015 & {$[226]$} \\
\hline $\mathrm{TiO}_{2} / \mathrm{rGO} / \mathrm{WO}_{3}$ & Z-Scheme & Disinfection & $97.3 \pm 3.8 \%$ of $E$. coli inactivation within 80 mins & 2017 & {$[227]$} \\
\hline $\mathrm{ZnO} / \mathrm{g}-\mathrm{C}_{3} \mathrm{~N}_{4} / \mathrm{rGO}$ & Type II & MB degradation & 99.5\% degradation efficiency within $15 \mathrm{~min}$ & 2015 & {$[228]$} \\
\hline $\mathrm{ZnO} / \mathrm{MoS}_{2} / \mathrm{RGO}$ & S-Scheme & $\mathrm{H}_{2}$ evolution & $\mathrm{H}_{2}$ production rate of $28.616 \mathrm{mmol} \mathrm{h}^{-1} \mathrm{~g}_{\mathrm{cat}^{-1}}$ & 2017 & {$[229]$} \\
\hline $\mathrm{Cd}_{0.5} \mathrm{Zn}_{0.5} \mathrm{~S} / \mathrm{g}-\mathrm{C}_{3} \mathrm{~N}_{4} / \mathrm{RGO}$ & S-Scheme & $\mathrm{H}_{2}$ evolution & $\mathrm{H}_{2}$ production rate of $39.24 \mathrm{mmol} \mathrm{g}^{-1} \mathrm{~h}^{-1}$ & 2018 & [230] \\
\hline $\mathrm{ZnO} / \mathrm{GQD}$ & Type II & MB degradation & $95 \%$ degradation within $70 \mathrm{~min}$ & 2018 & {$[231]$} \\
\hline $\mathrm{GQD} \mathrm{AgVO}_{3}$ & Type II & IBP degradation & 5 times higher than $\mathrm{AgVO}_{3}$ & 2016 & {$[232]$} \\
\hline $\mathrm{NaTaO}_{3} / \mathrm{g}-\mathrm{C}_{3} \mathrm{~N}_{4} / \mathrm{G}$ & Type II & MB degradation & $99 \%$ removal of $\mathrm{RhB}$ within $70 \mathrm{~min}$ & 2019 & {$[233]$} \\
\hline CdS/WS $/$ /graphene & Schottky & $\mathrm{H}_{2}$ evolution & $\mathrm{H}_{2}$ production rate of $1842 \mu \mathrm{mol} \mathrm{g}^{-1} \mathrm{~h}^{-1}$ & 2016 & {$[234]$} \\
\hline $\mathrm{TiO}_{2-x} / \mathrm{rGO}$ & Schottky & $\mathrm{H}_{2}$ production & $\mathrm{H}_{2}$ production rate of $16 \mathrm{mmol} \mathrm{g}^{-1} \mathrm{~h}^{-1}$ & 2016 & [235] \\
\hline
\end{tabular}



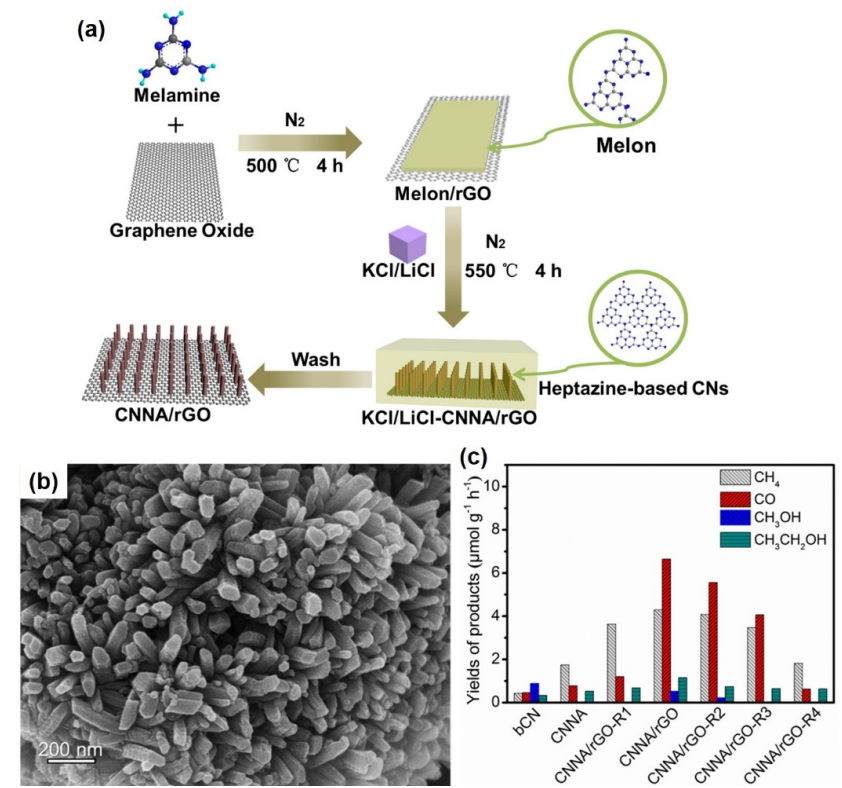

Fig. 24. (a) The schematical formation of CNNA/rGO composite in the molten salt medium. CNNA, rGO represents crystalline carbon nitride nanorods and reduced graphene oxide, respectively. (b) FESEM image of CNNA/rGO. (c) Photocatalytic $\mathrm{CO}_{2}$-reduction property of bulk $\mathrm{CN}$ (bCN), CNNA and CNNA/rGO at various amount of rGO in water vapor-saturated wet $\mathrm{CO}_{2}$ gas. (reproduced with permission [236], copyright 2019, Elsevier).

phene also acts as an ideal carrier of other semiconductor nanomaterials. He et al. [238] constructed a graphene-modified $\mathrm{WO}_{3} / \mathrm{TiO}_{2}$ S-scheme heterojunction composite photocatalyst via a facile one-step hydrothermal method, as shown in Fig. 26. The graphene sheet played two main roles in this novel composite. First, the rGO provided abundant adsorption and catalytically active sites as an ideal support. Second, the highly conduc-
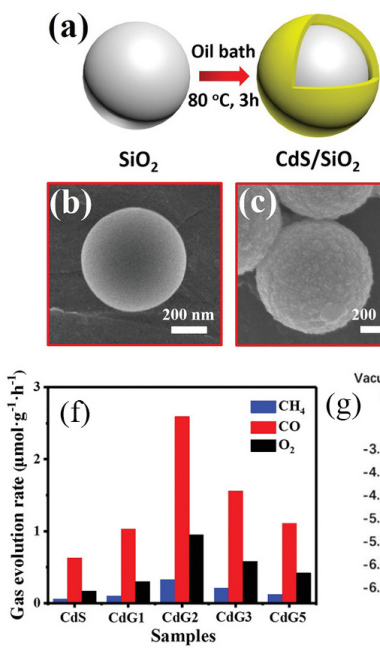

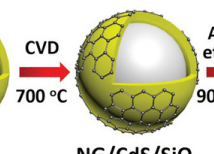
$\mathrm{NG} / \mathrm{CdS} / \mathrm{SiO}_{2}$
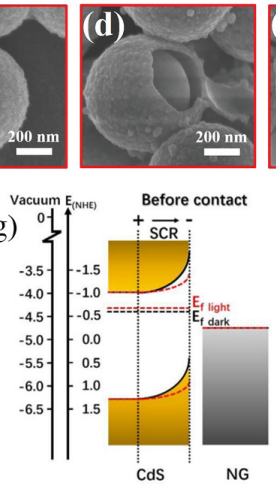

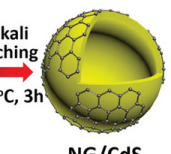
NG/CdS
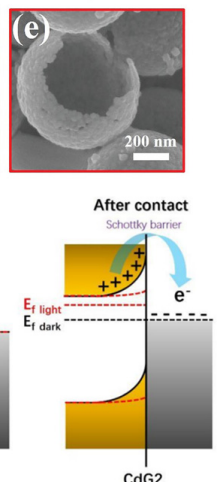

Fig. 25. (a) Schematic illustration of NG/CdS HS preparation process. (b-e) Corresponding SEM images of materials sequentially appear from left to right in (a). (f) Photocatalytic $\mathrm{CO}_{2}$ reduction performance of $\mathrm{CdS}$, CdG1, CdG2, CdG3, and CdG5. (g) Schematic illustration of the charge carrier migration mechanism. CdGx: $x$ donates that the dosage of pyridine during fabrication was $10 x \mu \mathrm{L}$. (reproduced with permission [237], copyright 2019, Wiley). tive rGO promoted electron separation and transfer from the conduction band of $\mathrm{TiO}_{2}$ by forming a Schottky junction between $\mathrm{TiO}_{2}$ and $\mathrm{rGO}$. The positive cooperative effect of the $\mathrm{WO}_{3} / \mathrm{TiO}_{2} \mathrm{~S}$-scheme heterojunction and the $\mathrm{TiO}_{2} / \mathrm{rGO}$ Schottky heterojunction suppressed the recombination of relatively useful electrons and holes. As a result, the $\mathrm{WO}_{3} / \mathrm{TiO}_{2} / \mathrm{rGO}$ composite shows much enhanced photocatalytic $\mathrm{H}_{2}$-evolution activity, which was $\sim 3.5$-fold that of pristine $\mathrm{TiO}_{2}$.

\section{Conclusion and outlook}

This review highlights the fundamental mechanism, designing strategy and recent achievements of different kinds of heterojunction-based photocatalysts, including type II heterojunctions, PN heterojunctions, Schottky heterojunctions, S-scheme heterojunctions, surface heterojunctions and graphene-base heterojunctions. Through the discussion on the application of these heterojunction materials in $\mathrm{H}_{2}$ production, $\mathrm{CO}_{2}$ reduction and pollutants degradation, it indicates that photocatalysis belongs to an important candidate technology to address the vital environment crisis. The recent achievements demonstrate that forming heterojunctions provides a promising approach to enhance the activity of photocatalysts, and thus a bright prospect to a better world.

The practical applications of photocatalysts are presently hindered by insufficient activity, poor stability, and high cost. There are drawbacks for each type of heterojunctions. For example, the type II heterojunction exhibits good charge separation efficiency, the redox reactions however, take place on the relatively lower potentials of the instituting semiconductors. And for a type II heterojunction, the internal electric field is against the charge movement that the band alignment is favorable for. It needs a n-type semiconductor and a p-type semiconductor to form a PN heterojunctions. Stronger internal field requires higher doping, which challenges the doping technology. For Schottky heterojunctions, the instituting metals are usually active and lack stability under the harsh environment where photocatalysts are supposed to work. The fabrication of
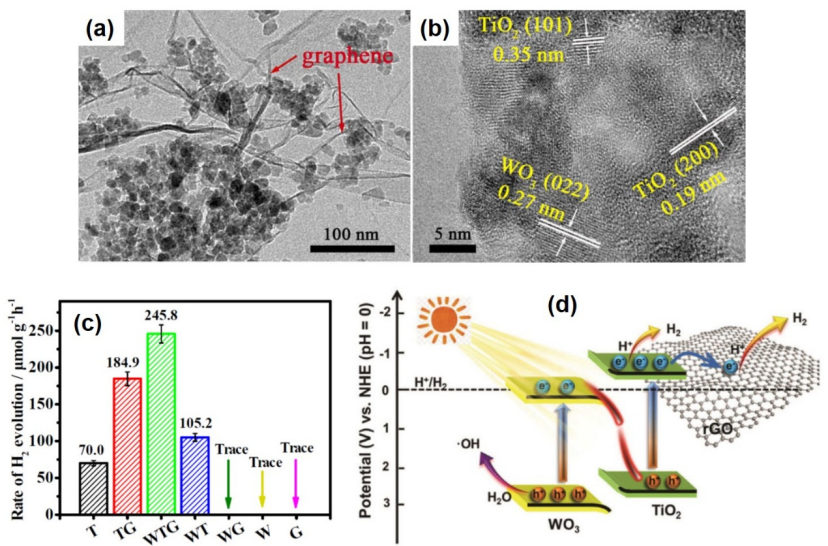

Fig. 26. TEM (a) and HRTEM (b) images of the $\mathrm{WO}_{3} / \mathrm{TiO}_{2} / \mathrm{rGO}$ (WTG) composite. (c) Photocatalytic activities of various samples. (d) Schematic illustration of the S-scheme heterojunction-based charge transfer mechanism in $\mathrm{WO}_{3} / \mathrm{TiO}_{2} / \mathrm{rGO}$ composite (reproduced with permission [238], copyright 2020, Elsevier). 
surface heterojunctions needs accurate control of the ratio of the exposed facets, which is extremely hard to achieve. The graphene-based heterojunctions benefit from the large surface area and high conductivity of graphene. However, it does not form new heterojunctions from the underlying mechanism.

Future opportunities in this field should fall in the following aspects. (1) In situ characterization technology. Although several theories have been proposed to explain the boosted separation of photogenerated electron-hole pairs across the heterojunction interfaces, a direct observation of the actual migration pathway of electron-hole pairs on real reactions is still missing. The improvement of the photocatalytic activity requires deeper understanding of the separation mechanism, which relies on the development of characterization equipment or technology, especially for in situ investigation. (2) New fabrication methods. Preparation of efficient heterojunction photocatalysts with a facile, controllable, and low-cost method remains challenging. New easier fabrication methods must be established to produce the engineered heterojunction materials with regulated composites, size, or morphology. Especially, methods of effective interface tuning with intimate contact between different semiconductor units are highly desirable. (3) New physical theories introducing to this field. Ultimately, the separation or recombination of electron-hole pairs roots in the movement of charged particles and the interaction with phonons. Up to date, the design of heterojunctions is accomplished within the classic theory framework. However, exotic behavior of electrons has been observed in novel materials, such as superconducting graphene or topological insulators. Possible introduction of these new physical theories in the heterojunction material field might lead to a thorough breakthrough.

\section{Conflicts of interest}

There are no conflicts to declare.

\section{References}

[1] D. Tong, Q. Zhang, Y. Zheng, K. Caldeira, C. Shearer, C. Hong, Y. Qin,
S. J. Davis, Nature, 2019, 572, 373-377.

[2] F. Egli, B. Steffen, T. S. Schmidt, Nat. Energy, 2018, 3, 1084-1092.

[3] S. Chu, Y. Cui, N. Liu, Nat. Mater., 2017, 16, 16-22.

[4] K. Takanabe, ACS Catal., 2017, 7, 8006-8022.

[5] W. Wang, X. Xu, W. Zhou, Z. Shao, Adv. Sci., 2017, 4, 1600371.

[6] Z. Guo, J. Zhou, L. Zhu, Z. Sun, J. Mater. Chem. A, 2016, 4, 11446-11452.

[7] Q. Wang, T. Hisatomi, Q. Jia, H. Tokudome, M. Zhong, C. Wang, Z. Pan, T. Takata, M. Nakabayashi, N. Shibata, Y. Li, I. D. Sharp, A. Kudo, T. Yamada, K. Domen, Nat. Mater., 2016, 15, 611-615.

[8] R. Shen, J. Xie, Q. Xiang, X. Chen, J. Jiang, X. Li, Chin. J. Catal., 2019, $40,240-288$.

[9] S. C. Roy, O. K. Varghese, M. Paulose, C. A. Grimes, ACS Nano, 2010, 4, 1259-1278.

[10] J. L. White, M. F. Baruch, J. E. Pander, Y. Hu, I. C. Fortmeyer, J. E. Park, T. Zhang, K. Liao, J. Gu, Y. Yan, T. W. Shaw, E. Abelev, A. B. Bocarsly, Chem. Rev., 2015, 115, 12888-12935.

[11] A. D. Tjandra, J. Huang, Chin. Chem. Lett., 2018, 29, 734-746.

[12] Y. Zhao, Z. Li, M. Li, J. Liu, X. Liu, G. I. N. Waterhouse, Y. Wang, J. Zhao, W. Gao, Z. Zhang, R. Long, Q. Zhang, L. Gu, X. Liu, X. Wen, D. Ma, L. Z. Wu, C. H. Tung, T. Zhang, Adv. Mater., 2018, 30, 1803127.

[13] X. Li, J. Yu, M. Jaroniec, X. Chen, Chem. Rev., 2019, 119, 3962-4179.

[14] J. Romão, G. Mul, ACS Catal., 2016, 6, 1254-1262.

[15] Y. Fan, W. Ma, D. Han, S. Gan, X. Dong, L. Niu, Adv. Mater., 2015, 27, 3767-3773.

[16] M. R. D. Khaki, M. S. Shafeeyan, A. A. A. Raman, W. M. A. W. Daud, J. Environ. Manage., 2017, 198, 78-94.

[17] X. Chen, Y. Li, X. Pan, D. Cortie, X. Huang, Z. Yi, Nat. Commun., 2016, $7,12273$.

[18] D. Friedmann, A. Hakki, H. Kim, W. Choi, D. Bahnemann, Green Chem., 2016, 18, 5391-5411.

[19] S. Kohtani, A. Kawashima, H. Miyabe, Front. Chem., 2019, 7, 630.

[20] D. W. Manley, J. C. Walton, Beilstein J. Org. Chem., 2015, 11, 1570-1582.

[21] H. Kisch, Acc. Chem. Res., 2017, 50, 1002-1010.

[22] Y. Markushyna, C. A. Smith, A. Savateev, Eur. J. Org. Chem., 2020, 2020, 1294-1309.

[23] A. Savateev, M. Antonietti, ChemCatChem, 2019, 11, 6166-6176.

[24] Z. Xing, J. Zhang, J. Cui, J. Yin, T. Zhao, J. Kuang, Z. Xiu, N. Wan, W. Zhou, Appl. Catal. B, 2018, 225, 452-467.

[25] J. Schneider, M. Matsuoka, M. Takeuchi, J. Zhang, Y. Horiuchi, M. Anpo, D. W. Bahnemann, Chem. Rev., 2014, 114, 9919-9986.

\section{Graphical Abstract}

Chin. J. Catal., 2021, 42: 710-730 doi: 10.1016/S1872-2067(20)63698-1

Advances in designing heterojunction photocatalytic materials

Zongpeng Wang, Zhiping Lin, Shijie Shen, Wenwu Zhong *, Shaowen Cao * Taizhou University; Wuhan University of Technology

This review systematically presents the working principles of various heterojunctions and summarize the recent innovative strategies for achieving high-performance heterojunction photocatalysts.

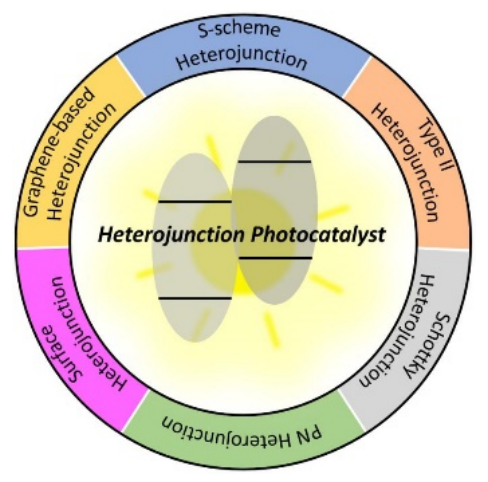


[26] S. Wei, S. Ni, X. Xu, Chin. J. Catal., 2018, 39, 510-516.

[27] K. Nakata, A. Fujishima, J. Photochem. Photobiol. C, 2012, 13, 169-189.

[28] R. Shi, Z. Li, H. Yu, L. Shang, C. Zhou, G. I. N. Waterhouse, L. Z. Wu, T. Zhang, ChemSusChem, 2017, 10, 4650-4656.

[29] L. Wang, P. Jin, S. Duan, H. She, J. Huang, Q. Wang, Sci. Bull., 2019, 64, 926-933.

[30] M. Zhou, S. Wang, P. Yang, C. Huang, X. Wang, ACS Catal., 2018, 8, 4928-4936.

[31] L. Shang, B. Tong, H. Yu, G. I. N. Waterhouse, C. Zhou, Y. Zhao, M. Tahir, L. Z. Wu, C. H. Tung, T. Zhang, Adv. Energy Mater., 2016, 6, 1501241.

[32] C. M. Wolff, P. D. Frischmann, M. Schulze, B. J. Bohn, R. Wein, P. Livadas, M. T. Carlson, F. Jäckel, J. Feldmann, F. Würthner, J. K. Stolarczyk, Nat. Energy, 2018, 3, 862-869.

[33] D. Ren, R. Shen, Z. Jiang, X. Lu, X. Li, Chin. J. Catal., 2020, 41, 31-40.

[34] Z. W. Zhang, Q. H. Li, X. Q. Qiao, D. Hou, D. S. Li, Chin. J. Catal., 2019, 40, 371-379.

[35] D. Ren, Z. Liang, Y. H. Ng, P. Zhang, Q. Xiang, X. Li, Chem. Eng. J., 2020, 390, 124496.

[36] Y. Wu, L. Zhang, Y. Zhou, L. Zhang, Y. Li, Q. Liu, J. Hu, J. Yang, Chin. J. Catal., 2019, 40, 691-702.

[37] K. Qi, B. Cheng, J. Yu, W. Ho, J. Alloys Compd., 2017, 727, 792-820.

[38] C. B. Ong, L. Y. Ng, A. W. Mohammad, Renew. Sust. Energy Rev., 2018, 81, 536-551.

[39] M. A, M. J, M. Ashokkumar, P. Arunachalam, Appl. Catal. A, 2018, $555,47-74$.

[40] T. Das, X. Rocquefelte, R. Laskowski, L. Lajaunie, S. Jobic, P. Blaha, K. Schwarz, Chem. Mater., 2017, 29, 3380-3386.

[41] H. L. Tan, R. Amal, Y. H. Ng, J. Mater. Chem. A, 2017, 5, 16498-16521.

[42] J. Jiang, S. Cao, C. Hu, C. Chen, Chin. J. Catal., 2017, 38, 1981-1989.

[43] J. Fu, J. Yu, C. Jiang, B. Cheng, Adv. Energy Mater., 2018, 8, 1701503.

[44] Y. Wang, Y. Li, S. Cao, J. Yu, Chin. J. Catal., 2019, 40, 867-874.

[45] J. Wang, S. Cao, J. Yu, Sol. RRL, 2020, 4, 1900469.

[46] P. Xia, M. Antonietti, B. Zhu, T. Heil, J. Yu, S. Cao, Adv. Funct. Mater., 2019, 29, 1900093

[47] B. Zhu, B. Cheng, L. Zhang, J. Yu, Carbon Energy, 2019, 1, 32-56.

[48] Y. Ren, D. Zeng, W. J. Ong, Chin. J. Catal., 2019, 40, 289-319.

[49] Y. Li, F. Gong, Q. Zhou, X. Feng, J. Fan, Q. Xiang, Appl. Catal. B, 2020, 268, 118381.

[50] J. Pan, Z. Dong, Z. Jiang, C. Zhao, B. Wang, W. Zhao, J. Wang, C. Song, Y. Zheng, C. Li, Sol. RRL, 2019, 3, 1900337.

[51] Y. Lu, Y. Lin, D. Wang, L. Wang, T. Xie, T. Jiang, Nano Res., 2011, 4, 1144-1152.

[52] M. Samadi, M. Zirak, A. Naseri, E. Khorashadizade, A. Z. Moshfegh, Thin Solid Films, 2016, 605, 2-19.

[53] P. Pascariu, I. V. Tudose, M. Suchea, E. Koudoumas, N. Fifere, A. Airinei, Appl. Surf. Sci., 2018, 448, 481-488.

[54] V. Kumaravel, S. Mathew, J. Bartlett, S. C. Pillai, Appl. Catal. B, 2019, 244, 1021-1064.

[55] D. C. Reynolds, D. C. Look, B. Jogai, J. E. Hoelscher, R. E. Sherriff, M. T. Harris, M. J. Callahan, J. Appl. Phys., 2000, 88, 2152-2153.

[56] A. Teke, Ü. Özgür, S. Doğan, X. Gu, H. Morkoç, B. Nemeth, J. Nause, H. O. Everitt, Phys. Rev. B, 2004, 70, 195207.

[57] J. Yu, S. Wang, J. Low, W. Xiao, Phys. Chem. Chem. Phys., 2013, 15, 16883-16890.

[58] J. Fu, Q. Xu, J. Low, C. Jiang, J. Yu, Appl. Catal. B, 2019, 243, 556-565.

[59] X. Du, I. Skachko, A. Barker, E. Y. Andrei, Nat. Nanotechnol., 2008, 3, 491-495.

[60] C. Sotelo-Vazquez, R. Quesada-Cabrera, M. Ling, D. O. Scanlon, A. Kafizas, P. K. Thakur, T. L. Lee, A. Taylor, G. W. Watson, R. G. Pal- grave, J. R. Durrant, C. S. Blackman, I. P. Parkin, Adv. Funct. Mater., 2017, 27, 1605413.

[61] S. A. Rawool, M. R. Pai, A. M. Banerjee, A. Arya, R. S. Ningthoujam, R. Tewari, R. Rao, B. Chalke, P. Ayyub, A. K. Tripathi, S. R. Bharadwaj, Appl. Catal. B, 2018, 221, 443-458.

[62] T. Paul, D. Das, B. K. Das, S. Sarkar, S. Maiti, K. K. Chattopadhyay, J. Hazard. Mater., 2019, 380, 120855.

[63] H. Yang, J. Li, L. Yu, B. Huang, Y. Ma, Y. Dai, J. Mater. Chem. A, 2018, 6, 4161-4166.

[64] J. Wang, H. Li, S. Meng, L. Zhang, X. Fu, S. Chen, Appl. Catal. B, 2017, 200, 19-30.

[65] A. S. Kshirsagar, P. K. Khanna, Mater. Chem. Front., 2019, 3, 437-449.

[66] A. Khampuanbut, S. Santalelat, A. Pankiew, D. Channei, S. Pornsuwan, K. Faungnawakij, S. Phanichphant, B. Inceesungvorn, J. Colloid Interface Sci., 2020, 560, 213-224.

[67] D. Li, W. Wu, Y. Zhao, R. Qiao, Mater. Lett., 2020, 271, 127709.

[68] Q. Wang, X. Wang, Z. Yu, X. Jiang, J. Chen, L. Tao, M. Wang, Y. Shen, Nano Energy, 2019, 60, 827-835.

[69] X. Jia, J. Cao, H. Lin, M. Zhang, X. Guo, S. Chen, Appl. Catal. B, 2017, 204, 505-514.

[70] E. Hua, S. Jin, X. Wang, S. Ni, G. Liu, X. Xu, Appl. Catal. B, 2019, 245, 733-742.

[71] M. G. Lee, D. H. Kim, W. Sohn, C. W. Moon, H. Park, S. Lee, H. W. Jang, Nano Energy, 2016, 28, 250-260.

[72] Z. Wang, W. Wu, Q. Xu, G. Li, S. Liu, X. Jia, Y. Qin, Z. L. Wang, Nano Energy, 2017, 38, 518-525.

[73] K. Dashtian, M. Ghaedi, H. Shirinzadeh, S. Hajati, S. Shahbazi, Chem. Eng. J., 2018, 339, 189-203.

[74] W. J. Kim, E. Jang, T. J. Park, Appl. Surf. Sci., 2017, 419, 159-164.

[75] C. Ji, S.-N. Yin, S. Sun, S. Yang, Appl. Surf. Sci., 2018, 434, 1224-1231.

[76] Y. P. Bhoi, B. G. Mishra, Chem. Eng. J., 2018, 344, 391-401.

[77] S. Joshi, S. J. Ippolito, M. V. Sunkara, RSC Adv., 2016, 6, 43672-43684.

[78] M. Zhang, H. Lin, J. Cao, X. Guo, S. Chen, Chem. Eng. J., 2017, 321, 484-494.

[79] J. Zhao, J. Nan, Z. Zhao, N. Li, J. Liu, F. Cui, Appl. Catal. B, 2017, 202, 509-517.

[80] J. Lin, Y. Liu, Y. Liu, C. Huang, W. Liu, X. Mi, D. Fan, F. Fan, H. Lu, X. Chen, ChemSusChem, 2019, 12, 961-967.

[81] M. A. Mahadadalkar, S. W. Gosavi, B. B. Kale, J. Mater. Chem. A, 2018, 6, 16064-16073.

[82] M. R. Shariati, A. Samadi-Maybodi, A. H. Colagar, J. Hazard. Mater., 2019, 366, 475-481.

[83] H. Cai, B. Wang, L. Xiong, J. Bi, L. Yuan, G. Yang, S. Yang, Appl. Catal. $B, 2019,256,117853$.

[84] C. Lu, F. Guo, Q. Yan, Z. Zhang, D. Li, L. Wang, Y. Zhou, J. Alloys Compd., 2019, 811, 151976.

[85] D. Liu, W. Cai, Y. Wang, Y. Zhu, Appl. Catal. B, 2018, 236, 205-211.

[86] G. T. S. T. da Silva, K. T. G. Carvalho, O. F. Lopes, C. Ribeiro, Appl. Catal. B, 2017, 216, 70-79.

[87] Y. Tang, R. Wang, Y. Yang, D. Yan, X. Xiang, ACS Appl. Mater. Inter., 2016, 8, 19446-19455.

[88] R. Kumar, D. Das, A. K. Singh, J. Catal., 2018, 359, 143-150.

[89] B. Wang, H. Yuan, J. Chang, X. Chen, H. Chen, Appl. Surf. Sci., 2019, 485, 375-380.

[90] X. Zhang, A. Chen, Z. Zhang, M. Jiao, Z. Zhou, Nanoscale Adv., 2019, 1, 154-161.

[91] J. Yu, W. Wang, B. Cheng, Chem-Asian J., 2010, 5, 2499-2506.

[92] N. Liang, M. Wang, L. Jin, S. Huang, W. Chen, M. Xu, Q. He, J. Zai, N. Fang, X. Qian, ACS Appl. Mater. Interfaces, 2014, 6, 11698-11705. 
[93] O. Mehraj, B. M. Pirzada, N. A. Mir, M. Z. Khan, S. Sabir, Appl. Surf. Sci., 2016, 387, 642-651.

[94] Z. Qin, M. Wang, R. Li, Y. Chen, Sci. China Mater., 2018, 61, 861-868.

[95] T. Xie, Y. Liu, H. Wang, Z. Wu, Appl. Surf. Sci., 2018, 444, 320-329.

[96] M. Pirhashemi, A. Habibi-Yangjeh, J. Mater. Sci. Technol., 2018, 34, 1891-1901.

[97] S. Liu, M. Zhao, Z. He, Y. Zhong, H. Ding, D. Chen, Chin. J. Catal., 2019, 40, 446-457.

[98] J. Pan, S. Li, Y. Liu, W. Ou, H. Li, W. Zhao, J. Wang, C. Song, Y. Zheng, C. Li, Chem. Eng. J., 2020, 382, 122813.

[99] Z. Wei, T. Xinyue, W. Xiaomeng, D. Benlin, Z. Lili, X. Jiming, F. Yue, S. Ni, Z. Fengxia, Chem. Eng. J., 2019, 361, 1173-1181.

[100] M. Yang, Y. Pu, W. Wang, J. Li, X. Guo, R. Shi, Y. Shi, J. Alloys Compd., 2019, 811, 151831.

[101] G. Swain, S. Sultana, K. Parida, ACS Sustain. Chem. Eng., 2020, 8, 4848-4862.

[102] N. R. Khalid, Z. Israr, M. B. Tahir, T. Iqbal, Int. J. Hydrogen Energy, 2020, 45, 8479-8489.

[103] J. Zhou, Z. Zhang, X. Kong, F. He, R. Zhao, R. Wu, T. Wei, L. Wang, J. Feng, Appl. Surf. Sci., 2020, 510, 145442.

[104] W. Zhao, Y. Liu, Z. Wei, S. Yang, H. He, C. Sun, Appl. Catal. B, 2016, $185,242-252$

[105] Y. Guo, J. Li, Z. Gao, X. Zhu, Y. Liu, Z. Wei, W. Zhao, C. Sun, Appl. Catal. B, 2016, 192, 57-71.

[106] Y. Xiang, P. Ju, Y. Wang, Y. Sun, D. Zhang, J. Yu, Chem. Eng. J., 2016, 288, 264-275.

[107] F. Duo, Y. Wang, X. Mao, X. Zhang, Y. Wang, C. Fan, Appl. Surf. Sci., 2015, 340, 35-42.

[108] Y. Chen, G. Zhu, M. Hojamberdiev, J. Gao, R. Zhu, C. Wang, X. Wei, P. Liu, J. Hazard. Mater., 2018, 344, 42-54.

[109] X. J. Wen, C. G. Niu, L. Zhang, G. M. Zeng, Dalton Trans., 2017, 46, 4982-4993.

[110] C. Liu, C. Cao, X. Luo, S. Luo, J. Hazard. Mater., 2015, 285, 319-324.

[111] Q. W. Cao, X. Cui, Y. F. Zheng, X. C. Song, J. Alloys Compd., 2016, 670, 12-17.

[112] X. Zou, Y. Dong, X. Zhang, Y. Cui, X. Ou, X. Qi, Appl. Surf. Sci., 2017, 391, 525-534.

[113] P. Senthil Kumar, M. Selvakumar, S. Ganesh Babu, S. Induja, S. Karuthapandian, J. Alloys Compd., 2017, 701, 562-573.

[114] S. Li, K. Xu, S. Hu, W. Jiang, J. Zhang, J. Liu, L. Zhang, Appl. Surf. Sci., 2017, 397, 95-103.

[115] X. F. Wu, Y. Sun, H. Li, Y. J. Wang, C. X. Zhang, J. R. Zhang, J. Z. Su, Y. W. Wang, Y. Zhang, C. Wang, M. Zhang, J. Alloys Compd., 2018, 740, 1197-1203.

[116] C. Yang, G. Gao, Z. Guo, L. Song, J. Chi, S. Gan, Appl. Surf. Sci., 2017, 400, 365-374.

[117] B. Li, X. Chen, T. Zhang, S. Jiang, G. Zhang, W. Wu, X. Ma, Appl. Surf. Sci., 2018, 439, 1047-1056.

[118] Y. Liu, S. Shen, J. Zhang, W. Zhong, X. Huang, Appl. Surf. Sci., 2019, 478, 762-769.

[119] H. Lu, Q. Hao, T. Chen, L. Zhang, D. Chen, C. Ma, W. Yao, Y. Zhu, Appl. Catal. B, 2018, 237, 59-67.

[120] Y. Ao, K. Wang, P. Wang, C. Wang, J. Hou, Appl. Catal. B, 2016, 194, 157-168.

[121] Y. Y. Cai, X. H. Li, Y. N. Zhang, X. Wei, K. X. Wang, J. S. Chen, Angew. Chem. Int. Ed., 2013, 52, 11822-11825.

[122] X. H. Li, M. Antonietti, Chem. Soc. Rev., 2013, 42, 6593-6604.

[123] X. H. Li, M. Baar, S. Blechert, M. Antonietti, Sci. Rep., 2013, 3, 1743.

[124] Q. He, S. Huang, C. Wang, Q. Qiao, N. Liang, M. Xu, W. Chen, J. Zai,
X. Qian, ChemSusChem, 2015, 8, 817-820.

[125] Q. Gu, Z. Gao, S. Yu, C. Xue, Adv. Mater. Interfaces, 2016, 3, 1500631.

[126] Z. Jiao, Z. Zhai, X. Guo, X. Y. Guo, J. Phys. Chem. C, 2015, 119, 3238-3243.

[127] W. Zhang, B. Wang, C. Hao, Y. Liang, H. Shi, L. Ao, W. Wang, J. Alloys Compd., 2016, 684, 445-452.

[128] H. Zhong, C. Yang, L. Fan, Z. Fu, X. Yang, X. Wang, R. Wang, Energy Environ. Sci., 2019, 12, 418-426.

[129] L. Pei, T. Li, Y. Yuan, T. Yang, J. Zhong, Z. Ji, S. Yan, Z. Zou, Chem. Commun., 2019, 55, 11754-11757.

[130] B. Li, S. Liu, C. Lai, G. Zeng, M. Zhang, M. Zhou, D. Huang, L. Qin, X. Liu, Z. Li, N. An, F. Xu, H. Yi, Y. Zhang, L. Chen, Appl. Catal. B, 2020, 266, 118650.

[131] S. Du, X. Lin, C. Li, G. Li, B. Zheng, Y. Liu, H. Xu, P. Fang, Chem. Eng. J., 2020, 389, 124431.

[132] R. Shen, W. Liu, D. Ren, J. Xie, X. Li, Appl. Surf. Sci., 2019, 466, 393-400.

[133] H. Liu, X. Liu, W. Yang, M. Shen, S. Geng, C. Yu, B. Shen, Y. Yu, J. Mater. Chem. A, 2019, 7, 2022-2026.

[134] R. Xiao, C. Zhao, Z. Zou, Z. Chen, L. Tian, H. Xu, H. Tang, Q. Liu, Z. Lin, X. Yang, Appl. Catal. B, 2020, 268, 118382.

[135] W. Zhong, S. Shen, M. He, D. Wang, Z. Wang, Z. Lin, W. Tu, J. Yu, Appl. Catal. B, 2019, 258, 117967.

[136] H. Yang, J. Tian, T. Li, H. Cui, Catal. Commun., 2016, 87, 82-85.

[137] X. J. Wang, X. Tian, Y. J. Sun, J. Y. Zhu, F. T. Li, H. Y. Mu, J. Zhao, Nanoscale, 2018, 10, 12315-12321.

[138] J. Tian, J. Li, N. Wei, X. Xu, H. Cui, H. Liu, Ceram. Int., 2016, 42, 1611-1617.

[139] Q. Leng, D. Yang, Q. Yang, C. Hu, Y. Kang, M. Wang, M. Hashim, Mater. Res. Bull., 2015, 65, 266-272.

[140] S. Wang, D. Chen, F. Niu, N. Zhang, L. Qin, Y. Huang, Appl. Phys. A, 2016, 122, 867.

[141] J. Hou, H. Cheng, C. Yang, O. Takeda, H. Zhu, Nano Energy, 2015, 18, 143-153.

[142] Q. Liu, Q. Shang, A. Khalil, Q. Fang, S. Chen, Q. He, T. Xiang, D. Liu, Q. Zhang, Y. Luo, L. Song, ChemCatChem, 2016, 8, 2614-2619.

[143] H. Xu, J. Yi, X. She, Q. Liu, L. Song, S. Chen, Y. Yang, Y. Song, R. Vajtai, J. Lou, H. Li, S. Yuan, J. Wu, P. M. Ajayan, Appl. Catal. B, 2018, 220, 379-385.

[144] Q. Zhang, J. Jia, J. Fan, X. Hu, E. Liu, D. Yang, Int. J. Hydrogen Energy, 2020, 45, 13340-13352.

[145] F. He, S. Wang, H. Zhao, Y. Wang, J. Zhang, Q. Yan, P. Dong, Z. Tai, L. Chen, Y. Wang, C. Zhao, Appl. Surf. Sci., 2019, 485, 70-80.

[146] Y. Fang, Y. Cao, Q. Chen, Ceram. Int., 2019, 45, 22298-22307.

[147] P. Kar, T. K. Maji, R. Nandi, P. Lemmens, S. K. Pal, Nano-Micro Lett., 2016, 9, 18-27.

[148] Y. Liu, X. Gu, W. Qi, H. Zhu, H. Shan, W. Chen, P. Tao, C. Song, W. Shang, T. Deng, J. Wu, ACS Appl. Mater. Interfaces, 2017, 9, 12494-12500.

[149] W. Zhao, T. Ding, Y. Wang, M. Wu, W. Jin, Y. Tian, X. Li, Chin. J. Catal., 2019, 40, 1187-1197.

[150] R. Shi, Y. Cao, Y. Bao, Y. Zhao, G. I. N. Waterhouse, Z. Fang, L. Z. Wu, C. H. Tung, Y. Yin, T. Zhang, Adv. Mater., 2017, 29, 1700803.

[151] K. M. Choi, D. Kim, B. Rungtaweevoranit, C. A. Trickett, J. T. D. Barmanbek, A. S. Alshammari, P. Yang, O. M. Yaghi, J. Am. Chem. Soc., 2017, 139, 356-362.

[152] L. Meng, Z. Chen, Z. Ma, S. He, Y. Hou, H. H. Li, R. Yuan, X. H. Huang, X. Wang, X. Wang, J. Long, Energy Environ. Sci., 2018, 11, 294-298.

[153] J. D. Xiao, L. Han, J. Luo, S. H. Yu, H. L. Jiang, Angew. Chem. Int. Ed., 2018, 57, 1103-1107. 
[154] Y. Hong, Y. Jiang, C. Li, W. Fan, X. Yan, M. Yan, W. Shi, Appl. Catal. $B$, 2016, 180, 663-673.

[155] B. Li, C. Lai, G. Zeng, L. Qin, H. Yi, D. Huang, C. Zhou, X. Liu, M. Cheng, P. Xu, C. Zhang, F. Huang, S. Liu, ACS Appl. Mater. Interfaces, 2018, 10, 18824-18836.

[156] D. Xu, B. Cheng, S. Cao, J. Yu, Appl. Catal. B, 2015, 164, 380-388.

[157] J. Low, B. Dai, T. Tong, C. Jiang, J. Yu, Adv. Mater., 2019, 31, 1802981.

[158] J. Hu, D. Chen, Z. Mo, N. Li, Q. Xu, H. Li, J. He, H. Xu, J. Lu, Angew. Chem. Int. Ed., 2019, 58, 2073-2077.

[159] L. Zhu, H. Li, P. Xia, Z. Liu, D. Xiong, ACS Appl. Mater. Interfaces, 2018, 10, 39679-39687.

[160] R. Shen, L. Zhang, X. Chen, M. Jaroniec, N. Li, X. Li, Appl. Catal. B, 2020, 266, 118619.

[161] D. Ren, W. Zhang, Y. Ding, R. Shen, Z. Jiang, X. Lu, X. Li, Sol. RRL, 2020, 4, 1900423.

[162] Z. Li, X. Wang, J. Zhang, C. Liang, L. Lu, K. Dai, Chin. J. Catal., 2019, 40, 326-334.

[163] X. Li, J. Xiong, Y. Xu, Z. Feng, J. Huang, Chin. J. Catal., 2019, 40, 424-433.

[164] F. Mei, K. Dai, J. Zhang, W. Li, C. Liang, Appl. Surf. Sci., 2019, 488, 151-160.

[165] J. Wang, Q. Zhang, F. Deng, X. Luo, D. D. Dionysiou, Chem. Eng. J., 2020, 379, 122264.

[166] T. Hu, K. Dai, J. Zhang, S. Chen, Appl. Catal. B, 2020, 269, 118844.

[167] S. Wang, X. Yang, X. Zhang, X. Ding, Z. Yang, K. Dai, H. Chen, Appl. Surf. Sci., 2017, 391, 194-201.

[168] T. Hu, K. Dai, J. Zhang, G. Zhu, C. Liang, Mater. Lett., 2019, 257, 126740.

[169] T. Di, B. Zhu, B. Cheng, J. Yu, J. Xu, J. Catal., 2017, 352, 532-541.

[170] T. Pan, D. Chen, W. Xu, J. Fang, S. Wu, Z. Liu, K. Wu, Z. Fang, J. Hazard. Mater., 2020, 393, 122366.

[171] F. Mei, Z. Li, K. Dai, J. Zhang, C. Liang, Chin. J. Catal., 2020, 41, 41-49.

[172] W. Zhao, Y. Feng, H. Huang, P. Zhou, J. Li, L. Zhang, B. Dai, J. Xu, F. Zhu, N. Sheng, D. Y. C. Leung, Appl. Catal. B, 2019, 245, 448-458.

[173] Z. Jin, R. Hu, H. Wang, J. Hu, T. Ren, Appl. Surf. Sci., 2019, 491, 432-442.

[174] D. Qin, Y. Xia, Q. Li, C. Yang, Y. Qin, K. Lv, J. Mater. Sci. Technol., 2020,

[175] X. Hu, G. Wang, J. Wang, Z. Hu, Y. Su, Appl. Surf. Sci., 2020, 511, 145499.

[176] Y. Ma, P. Lv, F. Duan, J. Sheng, S. Lu, H. Zhu, M. Du, M. Chen, J. Alloys Compd., 2020, 834, 155158.

[177] P. Xia, S. Cao, B. Zhu, M. Liu, M. Shi, J. Yu, Y. Zhang, Angew. Chem. Int. Ed., 2020, 59, 5218-5225.

[178] H. Ge, F. Xu, B. Cheng, J. Yu, W. Ho, ChemCatChem, 2019, 11, 6301-6309.

[179] X. Li, J. Xiong, X. Gao, J. Ma, Z. Chen, B. Kang, J. Liu, H. Li, Z. Feng, J. Huang, J. Hazard. Mater., 2020, 387, 121690.

[180] M. Zhang, M. Lu, Z. L. Lang, J. Liu, M. Liu, J. N. Chang, L. Y. Li, L. J. Shang, M. Wang, S. L. Li, Y. Q. Lan, Angew. Chem. Int. Ed., 2020, 59, 6500-6506.

[181] J. Yu, J. Low, W. Xiao, P. Zhou, M. Jaroniec, J. Am. Chem. Soc., 2014, 136, 8839-8842.

[182] R. Li, F. Zhang, D. Wang, J. Yang, M. Li, J. Zhu, X. Zhou, H. Han, C. Li, Nat. Commun., 2013, 4, 1432.

[183] R. Li, X. Tao, R. Chen, F. Fan, C. Li, Chem-Eur J., 2015, 21, 14337-14341.

[184] A. Meng, J. Zhang, D. Xu, B. Cheng, J. Yu, Appl. Catal. B, 2016, 198, 286-294.

[185] S. Gao, W. Wang, Y. Ni, C. Lu, Z. Xu, J. Alloys Compd., 2015, 647,
981-988.

[186] Y. Cao, Q. Li, C. Li, J. Li, J. Yang, Appl. Catal. B, 2016, 198, 378-388.

[187] X. Zhou, J. Wu, J. Zhang, P. He, J. Ren, J. Zhang, J. Lu, P. Liang, K. Xu, F. Shui, Mater. Lett., 2017, 205, 173-177.

[188] N. Liu, Y. Chang, Y. Feng, Y. Cheng, X. Sun, H. Jian, Y. Feng, X. Li, H. Zhang, ACS Appl. Mater. Interfaces, 2017, 9, 5907-5915.

[189] Z. Wei, Y. Zhao, F. Fan, C. Li, Comp. Mater. Sci., 2018, 153, 28-35.

[190] C. Gao, T. Wei, Y. Zhang, X. Song, Y. Huan, H. Liu, M. Zhao, J. Yu, X. Chen, Adv. Mater., 2019, 31, 1806596.

[191] Y. Zhu, Z. Zhang, N. Lu, R. Hua, B. Dong, Chin. J. Catal., 2019, 40, 413-423.

[192] J. Wang, B. Liu, K. Nakata, Chin. J. Catal., 2019, 40, 403-412.

[193] L. Mu, Y. Zhao, A. Li, S. Wang, Z. Wang, J. Yang, Y. Wang, T. Liu, R. Chen, J. Zhu, F. Fan, R. Li, C. Li, Energy Environ. Sci., 2016, 9, 2463-2469.

[194] T. Zheng, Y. Xia, X. Jiao, T. Wang, D. Chen, Nanoscale, 2017, 9, 3206-3211.

[195] R. Hailili, Z. Q. Wang, X. Q. Gong, C. Wang, Appl. Catal. B, 2019, 254, 86-97.

[196] H. L. Tan, X. Wen, R. Amal, Y. H. Ng, J. Phys. Chem. Lett., 2016, 7, 1400-1405.

[197] J. Lu, J. Wu, W. Xu, H. Cheng, X. Qi, Q. Li, Y. Zhang, Y. Guan, Y. Ling, Z. Zhang, Mater. Lett., 2018, 219, 260-264.

[198] J. Zhang, L. Zhang, Y. Shi, G. Xu, E. Zhang, H. Wang, Z. Kong, J. Xi, Z. Ji, Appl. Surf. Sci., 2017, 420, 839-848.

[199] J. Zhang, X. Ma, L. Zhang, Z. Lu, E. Zhang, H. Wang, Z. Kong, J. Xi, Z. Ji, J. Phys. Chem. C, 2017, 121, 6133-6140.

[200] Y. Wang, G. Tan, H. Ren, A. Xia, B. Li, D. Zhang, M. Wang, L. Lv, Mater. Lett., 2018, 229, 308-311.

[201] Q. Liu, Y. Liu, B. Gao, Y. Chen, B. Lin, Mater. Res. Bull., 2017, 87, 114-118.

[202] S. Sun, P. Gao, Y. Yang, P. Yang, Y. Chen, Y. Wang, ACS Appl. Mater. Interfaces, 2016, 8, 18126-18131.

[203] J. Zhang, D. Zhou, S. Dong, N. Ren, J. Hazard. Mater., 2019, 366, 311-320.

[204] Y. Wang, G. Tan, T. Liu, Y. Su, H. Ren, X. Zhang, A. Xia, L. Lv, Y. Liu, Appl. Catal. B, 2018, 234, 37-49.

[205] R. He, J. Zhang, J. Yu, S. Cao, J. Colloid Interface Sci., 2016, 478, 201-208.

[206] X. Li, R. Shen, S. Ma, X. Chen, J. Xie, Appl. Surf. Sci., 2018, 430 , 53-107.

[207] X. Li, J. Yu, S. Wageh, A. A. Al-Ghamdi, J. Xie, Small, 2016, 12, 6640-6696.

[208] N. Zhang, M. Q. Yang, S. Liu, Y. Sun, Y. J. Xu, Chem. Rev., 2015, 115, 10307-10377.

[209] S. Chen, T. Hisatomi, G. Ma, Z. Wang, Z. Pan, T. Takata, K. Domen, Chin. J. Catal., 2019, 40, 1668-1672.

[210] Y. F. Xu, M. Z. Yang, B. X. Chen, X. D. Wang, H. Y. Chen, D. B. Kuang, C. Y. Su, J. Am. Chem. Soc., 2017, 139, 5660-5663.

[211] Y. H. Si, Y. Xia, S. K. Shang, X. B. Xiong, X. R. Zeng, J. Zhou, Y. Y. Li, Nanomaterials, 2018, 8, 526.

[212] L. Yuan, C. Zhang, X. Zhang, M. Lou, F. Ye, C. R. Jacobson, L. Dong, L. Zhou, M. Lou, Z. Cheng, P. M. Ajayan, P. Nordlander, N. J. Halas, Nano Lett., 2019, 19, 4413-4419.

[213] D. Xu, B. Cheng, W. Wang, C. Jiang, J. Yu, Appl. Catal. B, 2018, 231, 368-380.

[214] E. Rokhsat, O. Akhavan, Appl. Surf. Sci., 2016, 371, 590-595.

[215] L. Yang, Y. Liu, R. Zhang, W. Li, P. Li, X. Wang, Y. Zhou, Chin. J. Catal., 2018, 39, 646-653.

[216] Q. Li, X. Li, S. Wageh, A. A. Al-Ghamdi, J. Yu, Adv. Energy Mater., 2015, 5, 1500010.

[217] Y. Liu, D. Zhang, J. Alloys Compd., 2017, 698, 60-67. 
[218] Y. Zhou, D. Li, L. Yang, C. Li, Y. Liu, J. Lu, Y. Wang, J. Mater. Sci.: Mater. El., 2017, 28, 7935-7942.

[219] S. Min, J. Hou, Y. Lei, X. Ma, G. Lu, Appl. Surf. Sci., 2017, 396, 1375-1382.

[220] Y. Jia, S. Li, J. Gao, G. Zhu, F. Zhang, X. Shi, Y. Huang, C. Liu, Appl. Catal. B, 2019, 240, 241-252.

[221] R. Yang, J. He, K. Song, Y. Fan, F. Tian, R. Zhu, Chem. Phys. Lett., 2020, 738, 136863.

[222] H. Li, P. Wang, X. Yi, H. Yu, Appl. Catal. B, 2020, 264, 118504.

[223] H. Zhang, Q. Q. Gu, Y. W. Zhou, S. Q. Liu, W. X. Liu, L. Luo, Z. D. Meng, Appl. Surf. Sci., 2020, 504, 144065.

[224] C. Liu, L. Zhang, R. Liu, Z. Gao, X. Yang, Z. Tu, F. Yang, Z. Ye, L. Cui, C. Xu, Y. Li, J. Alloys Compd., 2016, 656, 24-32.

[225] F. Li, L. Zhang, J. Tong, Y. Liu, S. Xu, Y. Cao, S. Cao, Nano Energy, 2016, 27, 320-329.

[226] X. Yang, J. Qin, Y. Jiang, K. Chen, X. Yan, D. Zhang, R. Li, H. Tang, Appl. Catal. B, 2015, 166-167, 231-240.

[227] X. Zeng, Z. Wang, G. Wang, T. R. Gengenbach, D. T. McCarthy, A. Deletic, J. Yu, X. Zhang, Appl. Catal. B, 2017, 218, 163-173.

[228] W. K. Jo, N. Clament Sagaya Selvam, J. Hazard. Mater., 2015, 299,
462-470.

[229] S. Kumar, N. L. Reddy, H. S. Kushwaha, A. Kumar, M. V. Shankar, K. Bhattacharyya, A. Halder, V. Krishnan, ChemSusChem, 2017, 10, 3588-3603.

[230] W. Xue, X. Hu, E. Liu, J. Fan, Appl. Surf. Sci., 2018, 447, 783-794.

[231] S. Kumar, A. Dhiman, P. Sudhagar, V. Krishnan, Appl. Surf. Sci, 2018, 447, 802-815.

[232] Z. D. Lei, J. J. Wang, L. Wang, X. Y. Yang, G. Xu, L. Tang, J. Hazard. Mater., 2016, 312, 298-306.

[233] F. Yang, L. Yan, B. Zhang, X. He, Y. Li, Y. Tang, C. Ma, Y. Li, J. Alloys Compd., 2019, 805, 802-810.

[234] Q. Xiang, F. Cheng, D. Lang, ChemSusChem, 2016, 9, 996-1002.

[235] L. Li, L. Yu, Z. Lin, G. Yang, ACS Appl. Mater. Interfaces, 2016, 8, 8536-8545.

[236] Y. Xia, Z. Tian, T. Heil, A. Meng, B. Cheng, S. Cao, J. Yu, M. Antonietti, Joule, 2019, 3, 2792-2805.

[237] C. Bie, B. Zhu, F. Xu, L. Zhang, J. Yu, Adv. Mater., 2019, 31, 1902868.

[238] F. He, A. Meng, B. Cheng, W. Ho, J. Yu, Chin. J. Catal., 2020, 41, 9-20.

\title{
异质结光催化材料的新进展
}

\author{
王宗鹏 ${ }^{\mathrm{a}, \mathrm{b}}$ ，林志萍 ${ }^{\mathrm{a}, \mathrm{c}}$ ，申士杰 ${ }^{\mathrm{a}, \mathrm{c}}$ ，钟文武 ${ }^{\mathrm{a}, \mathrm{c},{ }^{*}}$ ，曹少文 ${ }^{\mathrm{b}, \#}$ \\ a台州学院高等研究院, 浙江台州 318000

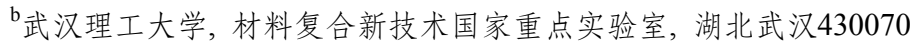 \\ c 台州学院医药化工与材料工程学院, 浙江台州 318000
}

摘要: 伴随着人类文明的快速发展,一些危机慢慢显露出来, 例如能源危机、环境污染和全球变暖. 2019年5月11日, Mauna Loa天文台报告, 大气中的二氧化碳水平超过 $415 \mathrm{ppm}$, 达到人类历史上的最高记录, 欧盟随后于 2019 年 11 月宣布了气候紧 急状态. 因此, 绿色能源技术已成为迫切需求, 以减少化石燃料的使用, 并减少污染物的产生.

光催化是直接利用太阳能的技术, 可以应用于水分解产氢、 $\mathrm{CO}_{2}$ 还原、降解有机污染物、促进有机物合成等, 是解决能 源和环境问题的最有前途的技术之一. 光催化剂是光催化技术的核心. 目前, 许多半导体材料可作为光催化剂, 并已被充 分地研究, 例如 $\mathrm{TiO}_{2} 、 \mathrm{CdS} 、 \mathrm{ZnO} 、 \mathrm{BiVO}_{4}$ 和 $\mathrm{C}_{3} \mathrm{~N}_{4}$ 等. 然而, 单一的半导体材料具有一些缺点, 阻碍了它们的实际应用. 其中, 限制这些半导体材料光催化活性的一个关键问题是, 光生电子-空穴对容易快速复合而不是参与光催化反应. 例如, $\mathrm{ZnO}$ 中 激子的寿命估计仅为数百皮秒, 大多数激子来不及参与到氧化还原反应中.

为了抑制电子-空穴对的复合, 需要应用特殊的策略. 构建异质结光催化材料已成为最有前途的方法之一. 通常, 可以 根据相邻材料的能带结构, 将异质结分为以下几种类型: PN型异质结, II型异质结, Schottky型异质结和 $\mathrm{S}$ 型异质结. 以上异 质结大都是由两种半导体材料复合而形成的. 除此之外, 还可以根据形成异质结的特殊材料, 补充两种特殊的异质结类型, 即晶面异质结和石墨烯基异质结. 晶面异质结是由同一材料, 由于暴露不同的晶面而形成的. 石墨烯具有独特的能带结 构、极大的比表面积及优良的导电性, 可以与其他半导体形成各种类型的异质结. 这些异质结材料能有效抑制电子-空穴对 的复合, 从而提高材料整体的光催化活性, 也已成为光催化剂家族的重要分支. 本文详细介绍了以上各种类型的异质结光 催化剂的最新进展, 概述了实现高性能异质结光催化剂的基本策略, 并对异质结光催化剂未来发展方向进行了一些探讨.

关键词: 光催化剂; 异质结; 可再生能源; 电荷转移; 氧化还原能力

收稿日期: 2020-04-29. 接受日期: 2020-07-10. 上网日期: 2020-09-22.

*通讯联系人. 电子信箱: zhongww@tzc.edu.cn

\#通讯联系人. 电子信箱: swcao@whut.edu.cn 基金来源：科技部重点研发项目(2018YFE0202601); 国家自然科学基金(11947070, 51572183, 51922081, 21773179); 浙江省一流 学科(P61021902); 浙江省自然科学基金(LTY20E020001).

本文的电子版全文由Elsevier出版社在ScienceDirect上出版(http://www.sciencedirect.com/science/journal/18722067). 